\title{
Exploiting Deep Eutectic Solvents and Organolithium Reagent Partnerships: Chemoselective Ultrafast Addition to Imines and Quinolines Under Aerobic Ambient Temperature Conditions
}

\author{
Cristian Vidal, ${ }^{[a]}$ Joaquín García-Álvarez, ${ }^{*[a]}$ Alberto Hernán-Gómez, ${ }^{[b]}$ Alan R. Kennedy ${ }^{[b]}$ and Eva \\ Hevia $^{*[b]}$
}

To the memory of Professor Jose Barluenga, a pioneer and an innovator in organometallic chemistry

\begin{abstract}
Shattering the long-held dogma that organolithium chemistry needs to be performed under inert atmospheres in toxic organic solvents, chemoselective addition of organolithium reagents to non-activated imines and quinolines has been accomplished in Green, biorenewable Deep Eutectic Solvents (DESs) at room temperature and in the presence of air, establishing a novel sustainable access to amines. Improving on existing methods, this approach proceeded in the absence of additives; occurred without competitive enolization, reduction or coupling processes; and reactions were completed in seconds. Comparing RLi reactivities in DESs with those observed in pure glycerol or THF suggests a kinetic anionic activation of the alkylating reagents occurs, favouring nucleophilic addition over competitive hydrolysis.
\end{abstract}

Nucleophilic addition of organolithium derivatives to carbonyl compounds (e.g., ketones or aldehydes) is a common methodology to access new $\mathrm{C}-\mathrm{C}$ bonds allowing synthesis of functionalized alcohols. ${ }^{[1]}$ Contrastingly, their use as nucleophiles to transform imines to amines via direct 1,2-addition processes has been significantly less developed. ${ }^{[2]}$ Reduced electrophilicity of the $\mathrm{C}=\mathrm{N}$ group, competitive abstraction of acidic $\mathrm{\alpha}-\mathrm{Hs}$ to give azaenolates and possible formation of reductive coupling sideproducts are some mitigating factors, which can compromise the chemoselectivity of this approach. ${ }^{[3]}$ Strategies undertaken to overcome these limitations include the use of Lewis acids (e.g., $\left.\mathrm{AlMe}_{3}, \mathrm{LiBr}\right)^{[4,5]}$ as additives that can activate the organic substrate and of alternative alkylating reagents such as magnesium zincates ([MgCl] $\left.\left[\mathrm{ZnR}_{3}\right]\right)$ which appear more chemoselective than conventional common $\mathrm{RLi}$ or $\mathrm{RMgX}$ reagents. ${ }^{[1,2]}$ However, all these protocols, as with nearly all methods using polar organometallics, require restrictive reaction conditions. This includes use of inert atmospheres, dry oxygenfree organic solvents and in many cases low temperatures (-78 ${ }^{\circ} \mathrm{C}$ ) in order to avoid intermediate degradation and side reactions. ${ }^{[6]}$ Thus, running polar organometallic chemistry under aerobic and/or hydrous conditions is the ultimate challenge to

[a] Dr. C. Vidal, Dr. J. García-Álvarez

Laboratorio de Compuestos Organometálicos y Catálisis (Unidad Asociada al CSIC)

Departamento de Química Orgánica e Inorgánica (IUQOEM),

Facultad de Química, Universidad de Oviedo,

E-33071, Oviedo, Spain.

E-mail: garciajoaquin@uniovi.es

[b] Dr. Hernán-Gómez, Dr A. R. Kennedy, Prof. E. Hevia WestCHEM, Department of Pure and Applied Chemistry University of Strathclyde, Glasgow, UK, G1 1XL

E-mail: eva.hevia@strath.ac.uk

Supporting information for this article is given via a link at the end of the document synthetic chemists. ${ }^{[7]}$ As an opening gambit towards this target, we recently pioneered use of green and biorenewable Deep Eutectic Solvents (DESs) combining ammonium salt choline chloride $(\mathrm{ChCl})$ with water or glycerol (Gly) (Fig. 1) showing they can activate Grignard and organolithium reagents to promote room temperature chemoselective ketone alkylation/arylation reactions. ${ }^{[8]}$ Moreover, air could be tolerated in these additions. Subsequent insightful studies by Capriati reported lithiation of diaryltetrahydrofurans in ChCl-based DESs under air, finding it competitive with protonolysis as well as RMgX and $\mathrm{RLi}$ mediated-additions to $\gamma$-chloroketones to furnish 2,2disubstituted tetrahydrofurans. ${ }^{[9]}$ Taking organolithium DES chemistry into new, more taxing territory, here we describe the chemoselective addition of organolithium compounds to both imines and quinolines in DESs under air as a novel sustainable methodology to amines. This has wide implications as amine synthesis has been identified as a key area in Green Chemistry for pharmaceutical manufacturers. ${ }^{[10]}$

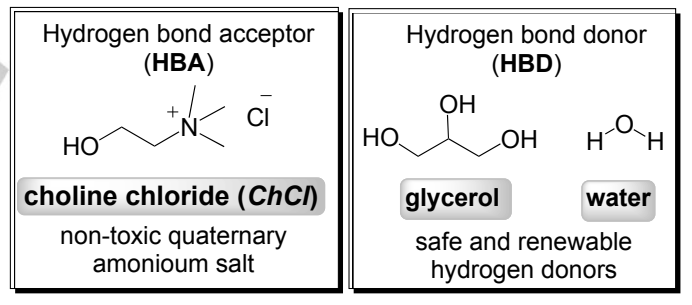

Figure 1: Components of DES mixtures used in this study.

This study examined adding $\mathrm{RLi}$ reagents to a range of imines at room temperature, in air, using DESs as solvents. ${ }^{[11]}$ The scope of this Green approach considered: (i) the DES combination, (ii) the organometallic reagent; and (iii) the imine. Firstly we assessed the reaction of commercially available ${ }^{n} \mathrm{BuLi}$ with aromatic imine $\mathrm{N}$-Benzylideneaniline (1a) using different stoichiometries [entries 1-4, Table 1] in the eutectic mixture $1 C h C / / 2 G / y$. Remarkably, under conditions incompatible with conventional organolithium chemistry, almost quantitative formation of amine (2a) was observed employing only slight excess of nBuLi (1.4 equiv., entry 2 ), in a very short reaction time (2-3 seconds). Advantages of this approach are that: (i) no additives are required to achieve high conversions; (ii) competitive enolization, reduction or coupling reactions were not observed;[12] (iii) edging closer to stoichiometric conditions, a slight excess of ${ }^{n} \mathrm{BuLi}$ gave full conversion to the desired amine 2a, even though hydrolysis could be expected in the protic solvent; and (iv) no imine decomposition was seen in the eutectic mixture. 
Table 1. Study of the addition reaction of organometallic reagents (RM = ${ }^{n} \mathrm{BuLi},{ }^{n} \mathrm{BuMgCl},{ }^{n} \mathrm{Bu}_{2} \mathrm{Mg}$ and $\mathrm{LiMg}^{n} \mathrm{Bu}_{3}$ ) to $\mathrm{N}$-Benzylideneaniline (1a) in different Deep Eutectic Solvents. ${ }^{[a, b]}$

\begin{tabular}{|c|c|c|c|c|}
\hline \multirow[b]{3}{*}{ Entry } & $\|_{1 a}^{N^{s^{P h}}}+$ & $\frac{D E}{\mathrm{rt}, \mathrm{unc}}$ & 2a & \multirow[b]{3}{*}{$\begin{array}{l}\text { Yield } \\
{[\%]^{\mathrm{c}}}\end{array}$} \\
\hline & \multicolumn{3}{|c|}{$\mathrm{RM}={ }^{n} \mathrm{BuLi},{ }^{n} \mathrm{BuMgCl},{ }^{n} \mathrm{Bu}_{2} \mathrm{Mg}$ or $\mathrm{LiMg}^{n} \mathrm{Bu}_{3}$} & \\
\hline & $\mathrm{RM}^{[\mathrm{b}]}$ & {$[\mathrm{mmol}]^{[\mathrm{b}]}$} & Solvent & \\
\hline 1 & ${ }^{n} \mathrm{BuLi}$ & 1.3 & $1 \mathrm{ChCl/2G/y}$ & 91 \\
\hline 2 & ${ }^{n} \mathrm{BuLi}$ & 1.4 & $1 \mathrm{ChCl/2Gly}$ & 95 \\
\hline 3 & ${ }^{n} \mathrm{BuLi}$ & 1.8 & $1 C h C / / 2 G l y$ & 97 \\
\hline 4 & ${ }^{n} \mathrm{BuLi}$ & 2 & $1 \mathrm{ChCl/2Gly}$ & 98 \\
\hline 5 & ${ }^{n} \mathrm{BuLi}$ & 1.4 & $1 C h C / / 2 E G$ & 66 \\
\hline 6 & ${ }^{n} \mathrm{BuLi}$ & 1.4 & 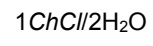 & 54 \\
\hline 7 & ${ }^{n} \mathrm{BuLi}$ & 1.4 & $\mathrm{H}_{2} \mathrm{O}$ & 22 \\
\hline 8 & ${ }^{n} \mathrm{BuLi}$ & 1.4 & Gly & 38 \\
\hline 9 & ${ }^{n} \mathrm{BuMgCl}$ & 1.4 & $1 C h C / / 2 G l y$ & 1 \\
\hline $10^{[d]}$ & ${ }^{n} \mathrm{BuMgCl}$ & 1.4 & $1 \mathrm{ChCl/2Gly}$ & 8 \\
\hline 11 & ${ }^{n} \mathrm{Bu}_{2} \mathrm{Mg}$ & 1.4 & $1 C h C / / 2 G l y$ & 36 \\
\hline 12 & $\mathrm{LiMg}^{n} \mathrm{Bu}_{3}$ & 1.4 & $1 \mathrm{ChCl/2Gly}$ & 72 \\
\hline
\end{tabular}

[a] Reactions were performed under air, at room temperature and using $1 \mathrm{~g}$ of $D E S$. Reaction time $3 \mathrm{~s} .1 \mathrm{mmol}$ of the imine $1 \mathrm{a}$ was always used. [b] Commercial solutions of ${ }^{n} \mathrm{BuLi}\left(1.6 \mathrm{M}\right.$ in hexanes), ${ }^{n} \mathrm{BuMgCl}(1.0 \mathrm{M}$ in THF) or dibutylmagnesium $\left(1.0 \mathrm{M}\right.$ in hexanes) were used. $\mathrm{LiMg}^{n} \mathrm{Bu}_{3}$ was prepared in situ by mixing equimolar amounts of ${ }^{n} \mathrm{BuLi}$ and ${ }^{n} \mathrm{Bu}_{2} \mathrm{Mg}$ in hexane. [c] Determined via ${ }^{1} \mathrm{H}$ NMR data using dibromomethane as internal standard. ${ }^{[d]}$ $\mathrm{ZnCl}_{2}(10 \mathrm{~mol} \%)$ was added to the reaction mixture.

Next we assessed the effect of different $\mathrm{ChCl}$-based DESs on this 1,2-addition reaction. Interestingly, replacing Gly for HBDs ethylene glycol ( $E G$, entry 5 ) and water (entry 6 ) lowers the yield of amine $2 \mathrm{a}$ (to 66 and $54 \%$ respectively). Notwithstanding, although the addition process is less efficient, its excellent chemoselectivity is maintained, without forming byproducts, as only unreacted imine $1 \mathbf{a}$ and amine $\mathbf{2 a}$ were seen in the reaction crudes (see SI). ${ }^{[13]}$ Contrastingly, when using HBDs containing carbonyl functionalities [such as urea or lactic acid], complex mixtures of products were observed from adding ${ }^{n} \mathrm{BuLi}$ across the $\mathrm{C}=\mathrm{O}$ bond of these $\mathrm{H}$-donor molecules, along with traces of $\mathbf{2 a}$. $^{[14]}$ Crucially, the use of inert-atmosphere Schlenk techniques or low temperature $\left(0\right.$ to $\left.-78^{\circ} \mathrm{C}\right)$, mandatory when these additions are carried out in ethereal solvents, are not required using DESs (these solvent mixtures have a high heat capacity, so low temperatures are not needed to cool reactions) ${ }^{[15]}$ The propensity of the DES mixture to favour ${ }^{n} \mathrm{BuLi}$ addition to $1 \mathrm{a}$ over its competing hydrolysis is illustrated in entries 7 and 8 of Table 1, whereas using neat $\mathrm{H}_{2} \mathrm{O}$ or $\mathrm{Gly}$, in the absence of ammonium salt $\mathrm{ChCl}$, furnishes $2 \mathrm{a}$ in lower 22 and $38 \%$ yields respectively.

Highlighting the exciting potential of these green solvents, when the addition order of the reagents is reversed and ${ }^{n} \mathrm{BuLi}$ is introduced firstly to the eutectic mixture, which is stirred for 15 seconds under air before adding imine $\mathbf{1 a}$, product $\mathbf{2 a}$ is obtained in a remarkably high $89 \%$ yield. Astonishingly, even if a one-minute interval is left between these reagents, the yield of
$2 \mathbf{a}$ is still good at $63 \%$, emphasising the kinetic stability of ${ }^{n} \mathrm{BuLi}$ in this green solvent. Indeed, it is only after 3.5 minutes when the formation of $\mathbf{2 a}$ is almost totally suppressed (Scheme 1 ).

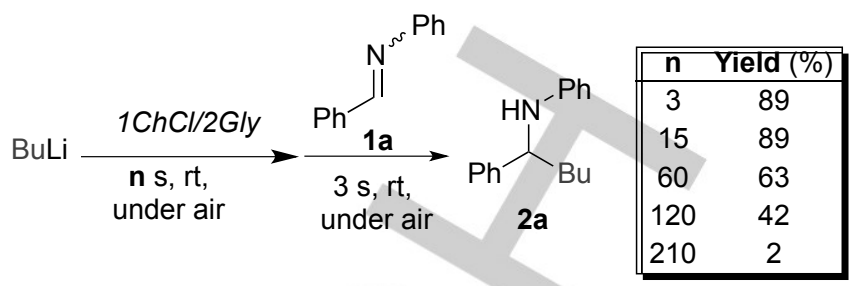

Scheme 1 Assessing the time-dependent formation of $2 \mathbf{a}$ when the order of addition of reagents is reversed

The reactivity of $1 \mathrm{a}$ with other polar organometallics under the optimized reaction conditions was also investigated. ${ }^{n} \mathrm{BuMgCl}$ failed to produce $2 \mathrm{a}$, even when $\mathrm{ZnCl}_{2}$ was employed as an additive (entries $9-10$ ). Using ${ }^{n} \mathrm{Bu}_{2} \mathrm{Mg}$, which has recently shown promise for addition to bis(aryl)methylimines in toluene, ${ }^{[16]}$ yields $2 \mathbf{a}$ in a modest $36 \%$ yield (entry 11 ). Even anionically activated lithium magnesiate $\mathrm{LiMg}^{n} \mathrm{Bu}_{3}$ showed reduced reactivity $(72 \%$, entry 12$)$, suggesting that under these conditions, the high polarity of $\mathrm{Li}-\mathrm{C}$ bonds in $\mathrm{RLi}$ reagents is crucial for success of the 1,2-addition process.

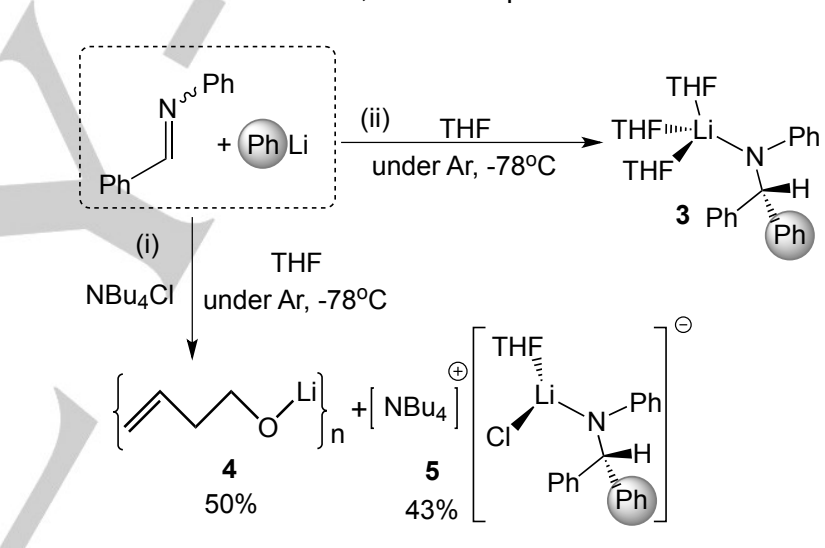

Scheme 2. Deleterious effect of ammonium salt on addition reaction between imine 1a and phenyllithium.

Our previous work related the enhanced reactivity of polar organometallics in DESs with studies on the addition of RMgX reagents to ketones in organic solvents, where chemoselectivity can be enhanced by adding substoichiometric amounts of ammonium salt $\mathrm{N}^{n} \mathrm{Bu}_{4} \mathrm{Cl}^{\left[{ }^{[8]}\right.} \mathrm{We}$ attributed this to forming kinetically activated mixed-ammonium magnesiate salts. Studies here reacting $\mathrm{PhLi}$ with $\mathbf{1 a}$ in THF in the presence of $\mathrm{N}^{n} \mathrm{Bu}_{4} \mathrm{Cl}$ suggest the formation of related mixed ammonium lithiate species. However, in this case, these compounds appear to be extremely reactive in THF solutions, having a negative effect on addition chemoselectivity. Thus NMR monitoring of the reaction revealed the formation of lithium but-3-en-1 oxide 4 , resulting from $\alpha$-deprotonation and subsequent ring-opening of THF (50\% yield) along with ammonium lithiate complex 5 (Scheme 2 (i)), whose constitution was established by ${ }^{1} \mathrm{H}$ DOSY NMR experiments (see $\mathrm{SI}$ ). Contrastingly, using $\mathrm{PhLi}$ the addition reaction occurs quantitatively to form amide $\left[(\mathrm{THF})_{3} \mathrm{LiNPh}\left(\mathrm{CHPh}_{2}\right)\right](3)$, whose structure was elucidated by $\mathrm{X}$ ray crystallography (Scheme 2 (ii) and $\mathrm{SI}$ ) This significant increase in the basicity of PhLi in THF on the addition of $\mathrm{N}^{n} \mathrm{Bu}_{4} \mathrm{Cl}$ contrasts with results observed using DESs, where no 
substantial metallation of the glycerol (HBD component of the $D E S$ ) is seen, hinting that though the formation of reactive ammonium lithiate species (via anionic activation by possible cocomplexation with $\mathrm{ChCl}$ ) can explain high efficiency of the addition reactions, other subtle effects such as the choice of HBD component or the nature of the ammonium salt employed should also play an important role in tuning the chemoselectivity of the reaction. Moreover, the different HBD abilities of water and alcohols cannot be disregarded, as recently shown by Capriati for "in water" RMgX mediated-additions to $\mathrm{Y}$ chloroketones. ${ }^{[9 \mathrm{c}]}$ Advancing the understanding of the interactions between the different components of DESs attracts widespread interest and debate, ${ }^{[11 a]}$ and to date only the structure of the DES reline (1ChC//2Urea) has been elucidated using neutron diffraction. ${ }^{[17]}$

Table 2. Addition of organolithium (RLi) reagents to imines in the eutectic mixture $1 \mathrm{ChCl/2G/y}$. ${ }^{[a]}$

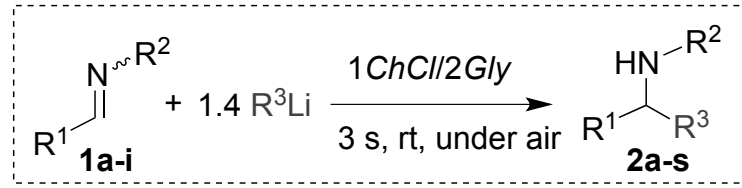

$\mathbf{2 a}_{\mathbf{2}(95 \%)}{ }_{2 \mathbf{b}(95 \%)}$

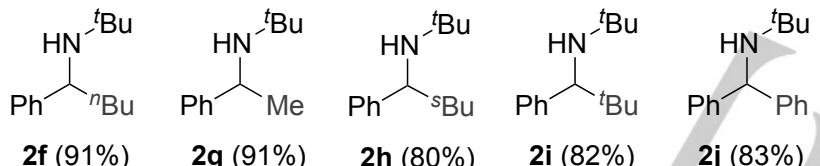$$
\mathbf{2 f}(91 \%) \quad \mathbf{2 g}(91 \%) \quad \mathbf{2 h}(80 \%) \quad \mathbf{2 i}(82 \%) \quad \mathbf{2 j}(83 \%)
$$<smiles>COc1ccc(NC(c2ccccc2)c2ccc(C)cc2)cc1</smiles>

$$
\mathbf{2 k}(73 \%) \quad \mathbf{2 l}(95 \%) \quad \mathbf{2 m}(82 \%) \quad \text { 2n }(86 \%)
$$<smiles>COc1ccc(C(Nc2ccccc2)c2ccc(C(Nc3ccccc3)c3ccccc3)cc2)cc1</smiles><smiles>COc1ccc(C(C)Nc2ccc(OC)c(NC(C)c3cc(Br)c(CC(C)(C)C)cc3Br)c2)cc1</smiles>

[a] Reactions were run under air, at room temperature using $1 \mathrm{~g}$ of the eutectic

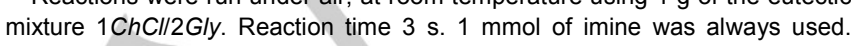
Commercial solutions of ${ }^{n} \mathrm{BuLi}$ (1.6 M in hexanes), MeLi (1.6 M in diethyl ether), ${ }^{s}$ BuLi (1.4 $\mathrm{M}$ in cyclohexane), ${ }^{t} \mathrm{BuLi}$ (1.9 $\mathrm{M}$ in pentane) and $\mathrm{PhLi}$ (1.8 $\mathrm{M}$ in dibutyl ether) were used. Yields were determined by ${ }^{1} \mathrm{H}$ NMR data using dibromomethane as internal standard.
Enthused by these findings we then ran the reaction using other RLi reagents and imines, to probe the scope of this transformation (see Table 2). For each substrate tested, the

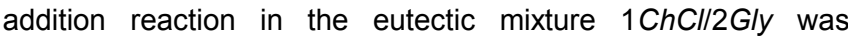
complete in a very short reaction time ( $3 \mathrm{~s})$ and with high selectivity, as only unreacted imine and the desired amine (2a-s) were observed in the reaction crudes (see $\mathrm{SI}$ ). Imine 1a was chosen as the benchmark to study the addition of different organolithium reagents. Thus, under the previously optimized reaction conditions (1.4 equiv. of $\mathrm{RLi}$, room temperature, under air, Table 1) both aliphatic ( $\left.{ }^{n} \mathrm{BuLi}, \mathrm{MeLi},{ }^{s} \mathrm{BuLi},{ }^{t} \mathrm{BuLi}\right)$ and aromatic $(\mathrm{PhLi})$ organolithium reagents successfully add to imine 1a yielding amines (2a-e) in excellent yields (86-95\%). Results are particularly remarkable with sterically demanding ${ }^{{ }^{\mathrm{B}} \mathrm{BuLi}}$ and ${ }^{t} \mathrm{BuLi}$, which in general have a greater tendency to undergo $\beta$ hydride elimination, especially when employed at room temperature. But here, they chemoselectively produce amines (2c-d and $\mathbf{2 h}-\mathbf{i}, 80-94 \%$ yield), without need of a large excess of RLi (1.4 equiv.) or long reaction times $(3 \mathrm{~s})$. The method also offers an excellent substrate scope, showing similar amine conversions for $\mathrm{N}$-aryl or $\mathrm{N}$-alkyl substituted aldimines (Table 2). High chemoselectivity is also apparent as electron-withdrawing $(\mathrm{Br} ; \mathbf{2 m}, \mathbf{2 q}$ and $\mathbf{2 s}$ ) and electron-donating substituents (MeO or Me; $\mathbf{2 k}, \mathbf{2 l}, \mathbf{2 n}, \mathbf{2 0}, \mathbf{2 p}$ and $\mathbf{2 r}$ ) are tolerated on imine Ar groups, without observing possible competing processes such as $\mathrm{Li}-\mathrm{Br}$ exchange (2m, $2 q$ and $\mathbf{2 s})$ or $\alpha$-metallation.

Table 3. Addition of organolithium $(\mathrm{RLi})$ reagents to quinolines in the eutectic mixture 1 ChCl/2Gly

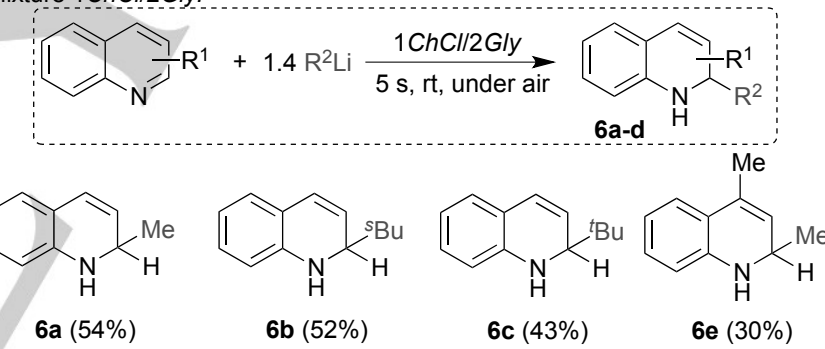

Reactions were performed under air, at room temperature using $1 \mathrm{~g}$ of the

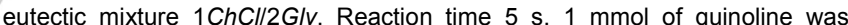
always employed. Commercial solutions of MeLi (1.6 M in diethyl ether), sBuLi (1.4 M in cyclohexane), and ${ }^{t} \mathrm{BuLi}$ (1.9 $\mathrm{M}$ in pentane) were used. Yields were determined by ${ }^{1} \mathrm{H}$ NMR data using dibromomethane as internal standard.

Next we extended this greener and air-compatible protocol to the even more challenging addition of organolithium reagents to aza-aromatic heterocyclic compounds which takes place with concomitant dearomatization of the heterocycle. The synthesis of 2-substituted dihydroquinolines, through adding RLi reagents to quinoline, is a commonly used methodology for the production of tetrahydroquinoline-containing alkaloids. ${ }^{[18]}$ Using conventional methods limited by low temperatures, an inert atmosphere and scrupulously dry solvents, these reactions usually yield mixtures of re-aromatized 2-substituted quinoline and $\mathrm{C} 2-$ and $\mathrm{C} 4$ dihydroquinolines. ${ }^{[19]}$ In contrast, we found that under the same optimized reaction conditions (1ChC//2Gly as solvent, at room temperature in air, $1.4 \mathrm{eq} \mathrm{RLi}$ in Table 3) aliphatic (MeLi, $\left.{ }^{s} \mathrm{BuLi},{ }^{t} \mathrm{BuLi}\right)$ organolithium reagents add instantaneously (5 s) to quinoline to furnish exclusively C2substituted dihydroquinolines $\mathbf{6 a - d}$. Although reaction yields are moderate $(30-54 \%)$, chemoselectivities are remarkable, as no by-products were seen in reaction crudes, only unreacted quinoline and target 2-substituted dihydroquinolines (see SI). 
In summary, this work has shown that replacing conventional toxic ethereal solvents by green, biorenewable Deep Eutectic Solvents facilitates the successful chemoselective addition of organolithium reagents to imines and quinolines under standard bench experimental conditions (room temperature and under air), thus edging closer towards reaching aerobic/hydrous polar organometallic chemistry and at the same time advancing Main-Group based Green Chemistry.

\section{Experimental Section}

Full experimental details and copies of NMR spectra are included in the Supporting Information. CCDC 1503241 contains supplementary crystallographic data for this paper. These data can be obtained free of charge from the Cambridge Crystallographic Data Centre.

\section{Acknowledgements}

We are indebted to Spanish MINECO (RYC-2011-08451, CTQ2013-40591-P, CTQ2014-51912-REDC), Gobierno del Principado de Asturias (GRUPIN14-006), and the EU COST SIPs-CM1302 for financial support. J. G.-A. thanks MINECO and the European Social Fund for award of a "Ramón y Cajal" contract. EH, AHG thank the ERC (Stg MixMetApps) for its generous sponsorship of this research. Authors also thank Professor Robert E. Mulvey for his insightful comments.
S. Ryder, Chem. Rev., 2014, 114, 11060; (c) D. A. Alonso, A. Baeza, C. Chinchilla, R. G. Guillena, I. M. Pastor, D. J. Ramón, Eur. J. Org. Chem., 2016, 612. (d) A. P. Abbott, G. Capper, D. L. Davies, R. K. Rasheed, V. Tambyrajah, Chem. Commun. 2003, 70.

[12] R. Bloch, Chem. Rev., 1998, 98, 1407.

[13] It should be noted that benzaldehyde (the hydrolyzed product of imine 1a) was not formed in the reaction using eutectic mixture $1 \mathrm{ChCl} / 2 \mathrm{H}_{2} \mathrm{O}$.

[14] A similar behavior has been noted by us for the addition of $\mathrm{RMgX}$ to ketones using DESs, see ref 8 .

[15] Molar heat capacity for DESs based on quaternary ammonium salts and several hydrogen bond donors (i.e. G/y) have been recently reported in the temperature range of $298.15-353.15 \mathrm{~K}$. J. Naser, F. S. Mjalli, Z. S. Gano, J. Chem. Eng. Data., 2016, $61,1608$.

[16] A. Desmarchelier, P. Ortiz, S. R. Harutyunyan, Chem. Commun., 2015, 51, 703.

[17] O. S. Hammond, D. T. Bowron, K. J. Edler, Green Chem., 2016, 18, 2736

[18] I. Jacquemond-Collet, F. Benoit-Vical, M. A. Valentin, E. Stanislas, M. Mallié, I. Fourasté, Planta Med., 2002, 68, 68.

[19] (a) A. Alexakis, F. Amiot, Tetrahedron: Asymmetry, 2002, 13 2117; (b) F. Amiot, L. Cointeaux, E. J. Silve, A. Alexakis, Tetrahedron, 2004, 60, 8221; (c) A. O'Byrne, P. Evans, Tetrahedron, 2008, 64, 8067;

Keywords: Organolithium reagents - Deep Eutectic Solvents • Green Chemistry $\bullet$ salt activation $\bullet$ Imines •

[1] (a) The Chemistry of Organomagnesium Compounds, Z Rappoport, I. Marek, Eds., Patai Series, Wiley, Chichester, UK, 2008; (b) J. Clayden, Organolithiums: Selectivity for Synthesis. Pergamon, Elsevier Science Ltd., Oxford, UK, 2002.

[2] Selected examples of 1,2-addition of organolithiums to imines: (a) D. A. Cogan, J. A. Ellman, J. Am. Chem. Soc., 1999, 121, 268; (b) J. L. Rutherford, D. Hoffmann, D. B. Collum, J. Am. Chem. Soc., 2002, 124, 265; (c) G. Wu, M. Huang, Chem. Rev., 2006, 106, 2596; (d) P. Liu, Z. J. Liu, F. Wu, Adv. Synth. Catal., 2015, 357, 818.

[3] J. S. Dickstein, M.C. Kozlowski, Chem. Soc. Rev., 2008, 37, 1166.

[4] A. W. Patterson, J. A. Ellman, J. Org. Chem., 2006, 71, 7110.

[5] V. Pace, L. Castoldi, P. Hoyos, J. V. Sinisterra, M. Pregnolato, J. M. Sánchez-Montero, Tetrahedron, 2011, 67, 2670.

[6] M. Hatano, S. Suzuki, K. Ishihara, J. Am. Chem. Soc., 2006 , 128, 9998.

[7] For a review on the use of polar organometallics in unconventional solvents see: V. Capriati, J. García-Álvarez, E. Hevia, Eur. J. Org. Chem., 2015, 6779 and references therein.

[8] C. Vidal, J. García-Álvarez, A. Hernán-Gómez, A. R. Kennedy, E. Hevia, Angew. Chem. Int. Ed., 2014, 53, 5969.

[9] (a) V. Mallardo, R. Rizzi, F. C. Sassone, R. Mansueto, F. M. Perna, A. Salomone, V. Capriati, Chem. Commun., 2014, 50 8655; (b) F. C. Sassone, F. M. Perna, A. Salomone, S. Florio V. Capriati, Chem. Commun., 2015, 51, 9459; (c) L. Cicco, S. Sblendorio, R. Mansueto, F. M. Perna, A. Salomone, S. Florio, V. Capriati, Chem. Sci., 2016, 7, 1192.

[10] D. J. C. Constable, P. J. Dunn, J. D. Hayler, G. R. Humphrey, J. L. Leazer, Jr., R. J. Linderman, K. Lorenz, J. Manley, B. A. Pearlman, A. Wells, A. Zaksh, T. Y. Zhang, Green Chem., 2007, 9, 411.

[11] (a) M. Francisco, A. van den Bruinhorst, M. C. Kroon, Angew. Chem. Int. Ed., 2013, 52, 3074; (b) E. L. Smith, A. P. Abbott, K. 
Entry for the Table of Contents (Please choose one layout)

Layout 1:

\section{COMMUNICATION}

The Green(air), the better!

Moving closer to the dream of hydrous/aerobic organolithium chemistry, replacing toxic organic solvents by green and biorenewable Deep Eutectic Solvents (DESs) enables regioselective addition of organolithium reagents to nonactivated imines at room temperature in air.

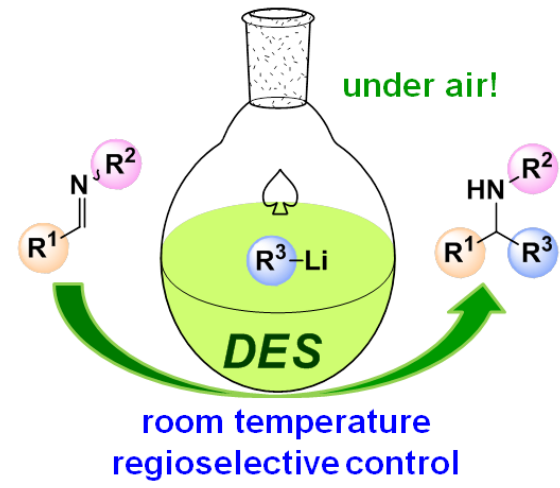

C. Vidal, J. García-Álvarez, * A. HernánGómez, A. R. Kennedy, and E. Hevia*

Page No. - Page No.

Title

Layout 2:

\section{COMMUNICATION}

((Insert TOC Graphic here))

Text for Table of Contents
Author(s), Corresponding Author(s)*

Page No. - Page No.

Title 


\section{Angewandte}

Supporting Information

Exploiting Deep Eutectic Solvents and Organolithium Reagent Partnerships: Chemoselective Ultrafast Addition to Imines and Quinolines Under Aerobic Ambient Temperature Conditions

Cristian Vidal, Joaquín García-Álvarez,* Alberto Hernán-Gómez, Alan R. Kennedy, and Eva Hevia*

anie_201609929_sm_miscellaneous_information.pdf 


\section{Table of Contents}

$\begin{array}{ll}\text { General Methods } & \text { S2 }\end{array}$

General procedure for addition reactions of $\mathrm{RLi}$ reagents with imines in $\mathrm{S} 2$ DESS

General procedure for addition reactions of $R L i$ reagents with S12 quinolines in $D E S$

Synthesis and X-Ray Crystal Structure Determination of Compound $3 \quad$ S15 Addition reaction of $\mathrm{LiPh}$ towards $\mathrm{PhNC}(\mathrm{H}) \mathrm{NPh}$ in presence of $\mathrm{NBu}_{4} \mathrm{Cl} \quad \mathrm{S} 18$ References 
General Methods. All reagents were obtained from commercial suppliers and used without further purification with the exception of the Deep Eutectic Solvents ${ }^{1}$ and imines $\mathbf{1} \mathbf{c}-\mathbf{i}^{2}$ which were prepared by following the methods reported in the literature. Organolithium reagents were obtained from commercial suppliers: (i) $n$-butyl lithium (1.6 M solution in hexane); (ii) methyl lithium (1.6 M solution in diethyl ether); (iii) sec-butyl lithium (1.4 M solution in cyclohexane); (iv) tert-butyl lithium (1.9 M solution in pentane) and (v) phenyl lithium (1.8 M in dibutyl ether). The concentration of these solutions was established by titration with salicylaldehyde phenylhydrazone. ${ }^{3}$ Solvent free PhLi was prepared as a solid and stored in the glove box, following the reported procedure. ${ }^{4}$ NMR spectra were recorded on a Bruker DPX $400 \mathrm{MHz}$ spectrometer, operating at $400.13 \mathrm{MHz}$ for ${ }^{1} \mathrm{H}, 150.32 \mathrm{MHz}$ for ${ }^{7} \mathrm{Li}$ and $100.62 \mathrm{MHz}$ for ${ }^{13} \mathrm{C}$. Elemental analyses were carried out on a Perkin-Elmer 2400 elemental analyser.

\section{General procedure for addition reactions of RLi reagents with imines in DESs.}

Syntheses were performed under air and at room temperature. In a glass tube, the appropriate imine (1a-1i, $1 \mathrm{mmol})$ was dissolved in the corresponding Deep Eutectic Solvent (DES, $1 \mathrm{~g})$ under air, followed by the addition of the organolithium reagent (RLi, $1.4 \mathrm{mmol}$ ) at room temperature, and the reaction mixture was stirred for 3 seconds. The reaction is stopped by addition of a saturated solution of the Rochelle salt (sodium potassium tartrate tetrahydrate) and the organic products were extracted with $\mathrm{Et}_{2} \mathrm{O}(3 \times 5 \mathrm{~mL})$. The combined organic extracts were dried over $\mathrm{MgSO}_{4}$ and the solvent removed under reduced pressure. Yields of the reaction crudes were determined by ${ }^{1} \mathrm{H}$ NMR methodology using dibromomethane $(1 \mathrm{mmol}, 70.8 \mu \mathrm{L})$ as internal standard. Amines 2a-s are known compounds and their ${ }^{1} \mathrm{H}$ NMR spectroscopic data matched with that reported in the literature. ${ }^{2,5}$

X-ray crystallography. Data for sample 3, were measured with an Oxford Diffraction diffractometer ${ }^{6}$ with monochromated Mo K $\alpha(\lambda=0.71073 \AA)$ radiation. Refinement was to convergence on $F^{2}$ and against all independent reflections by the full-matrix least squares method using the SHELXL program. ${ }^{7}$ Selected crystallographic and refinement details are given in Table ESI-1. CCDC 1503241 contains supplementary crystallographic data for this paper. These data can be obtained free of charge from the Cambridge Crystallographic Data Centre. 


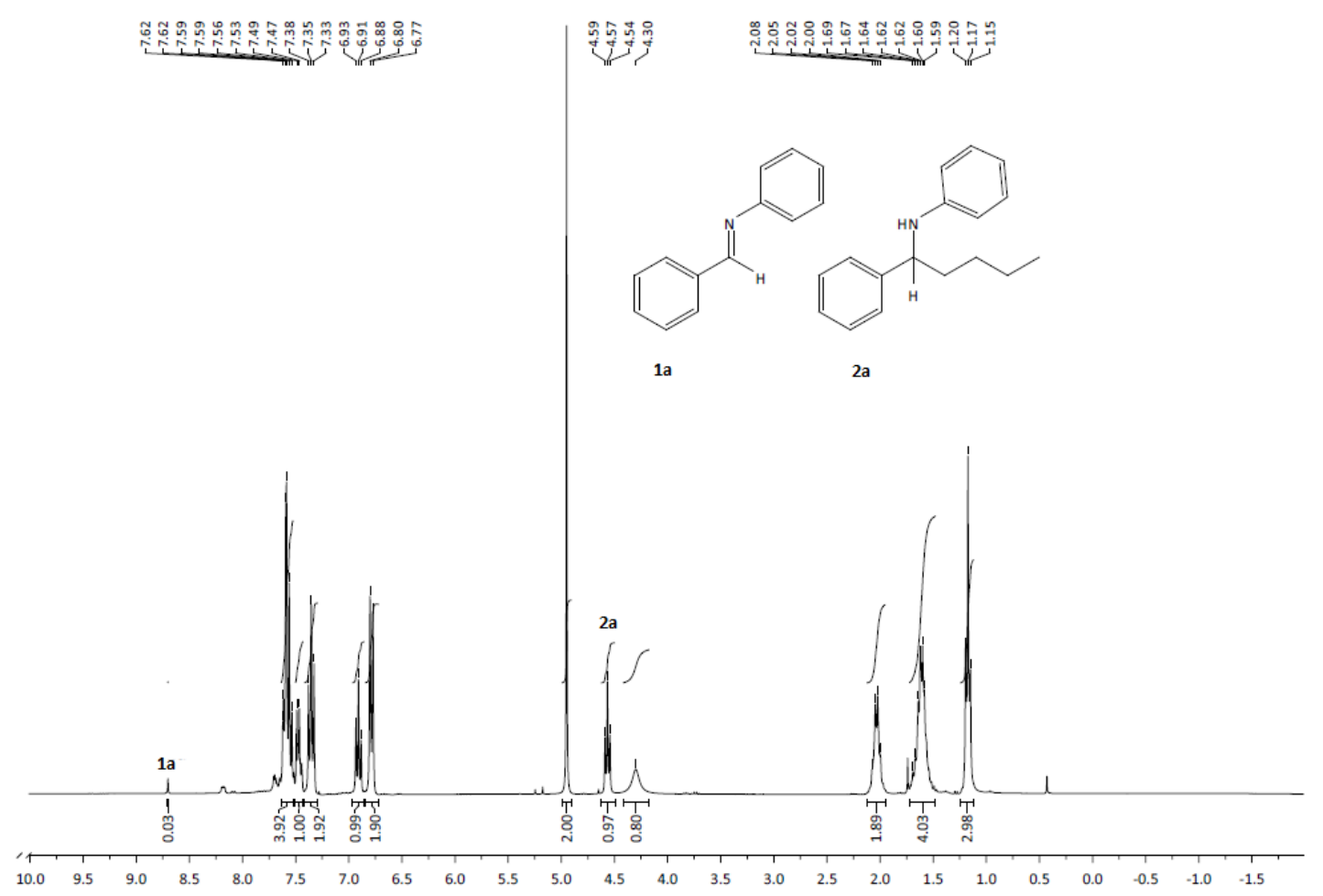

Figure ESI-1. ${ }^{1} \mathrm{H}$ NMR spectrum of the reaction crude from the addition of ${ }^{n} \mathrm{BuLi}$ to $\mathrm{N}$ benzylideneaniline (1a) in $1 \mathrm{ChCl} / 2 \mathrm{Gly}$, using $\mathrm{CH}_{2} \mathrm{Br}_{2}(4.9 \mathrm{ppm})$ as internal standard in $\mathrm{CDCl}_{3}$.

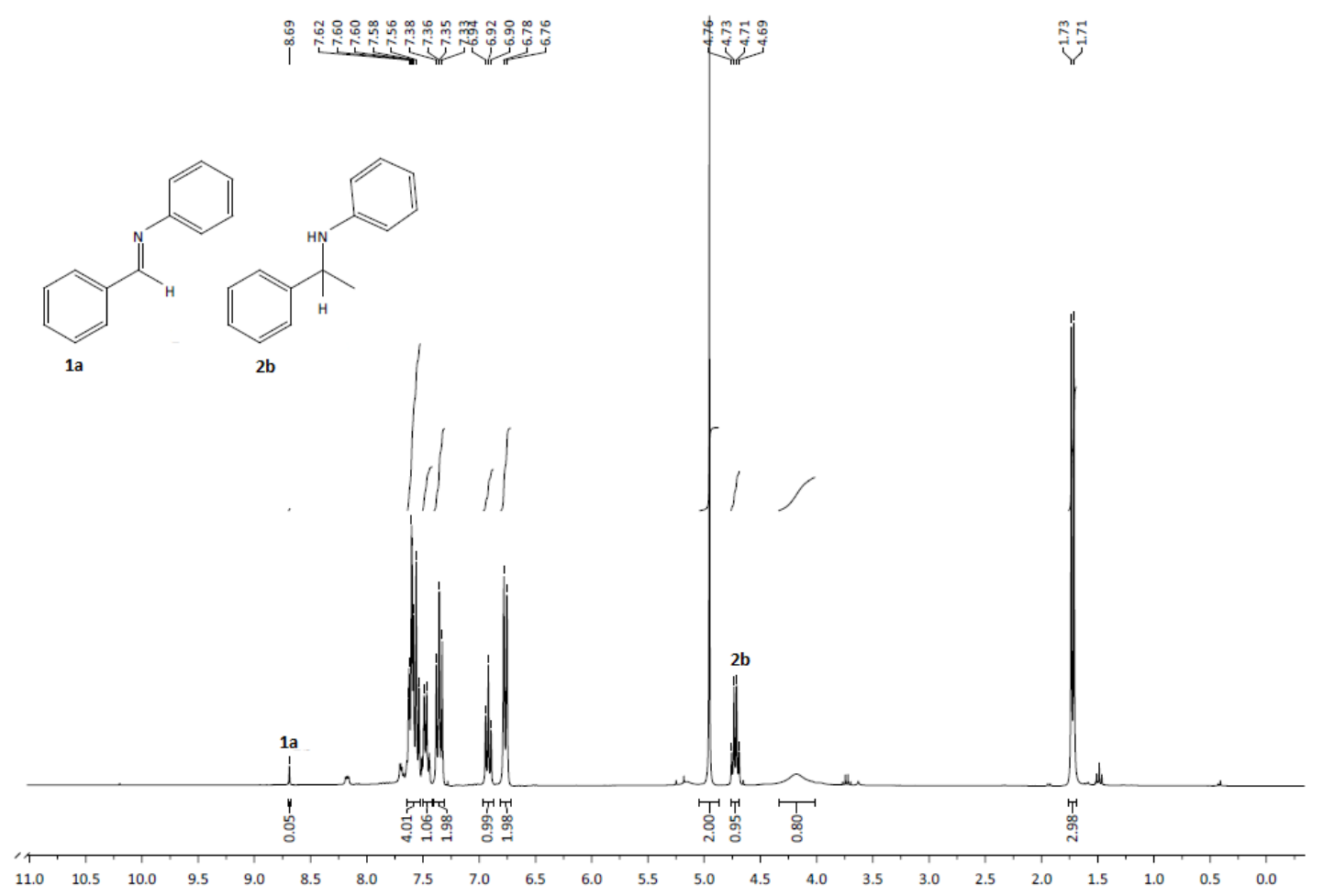

Figure ESI-2. ${ }^{1} \mathrm{H}$ NMR spectrum of the reaction crude from the addition of MeLi to $\mathrm{N}$ benzylideneaniline (1a) in $1 \mathrm{ChCl} / 2 \mathrm{Gly}$, using $\mathrm{CH}_{2} \mathrm{Br}_{2}(4.9 \mathrm{ppm})$ as internal standard in $\mathrm{CDCl}_{3}$. 


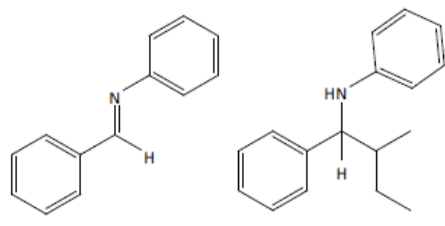

1a

$2 \mathrm{c}$
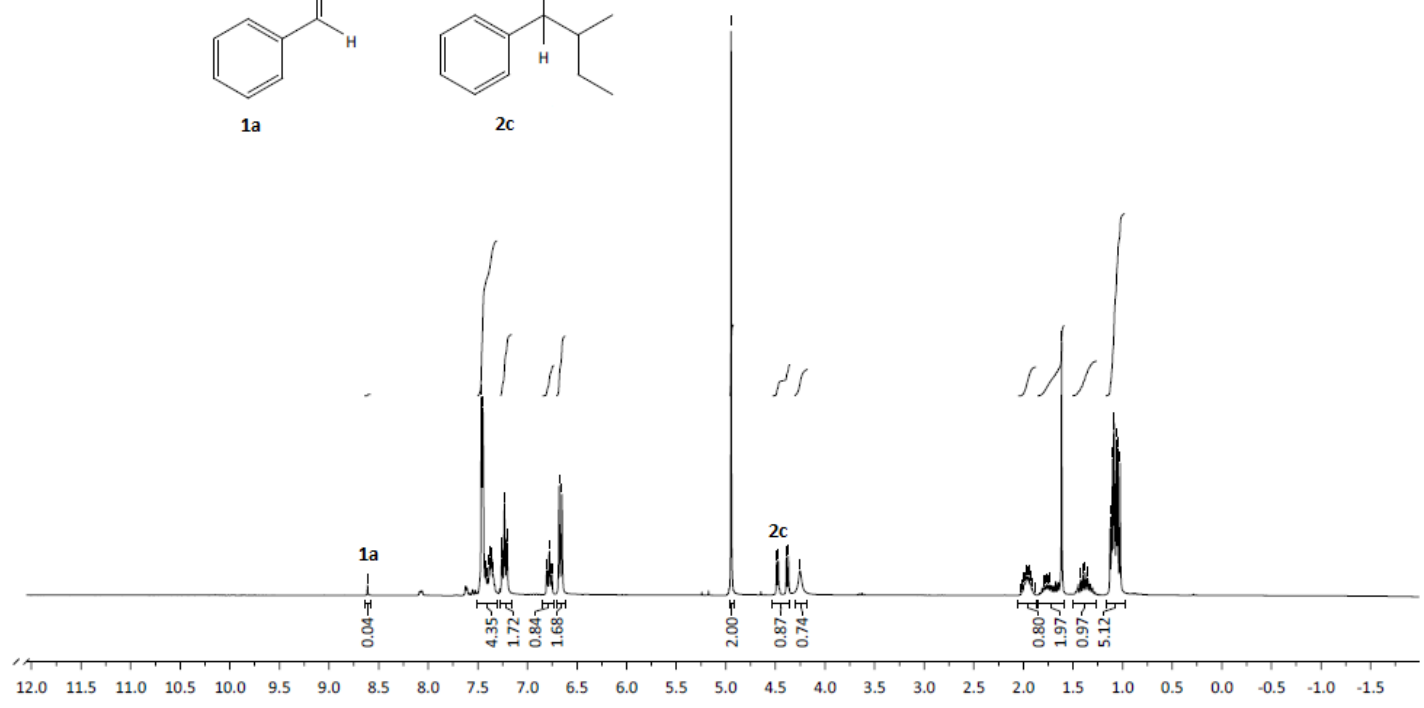

Figure ESI-3. ${ }^{1} \mathrm{H}$ NMR spectrum of the reaction crude from the addition of ${ }^{s} \mathrm{BuLi}$ to $\mathrm{N}$ benzylideneaniline (1a) in $1 \mathrm{ChCl} / 2 \mathrm{Gly}$, using $\mathrm{CH}_{2} \mathrm{Br}_{2}(4.9 \mathrm{ppm})$ as internal standard in $\mathrm{CDCl}_{3}$.
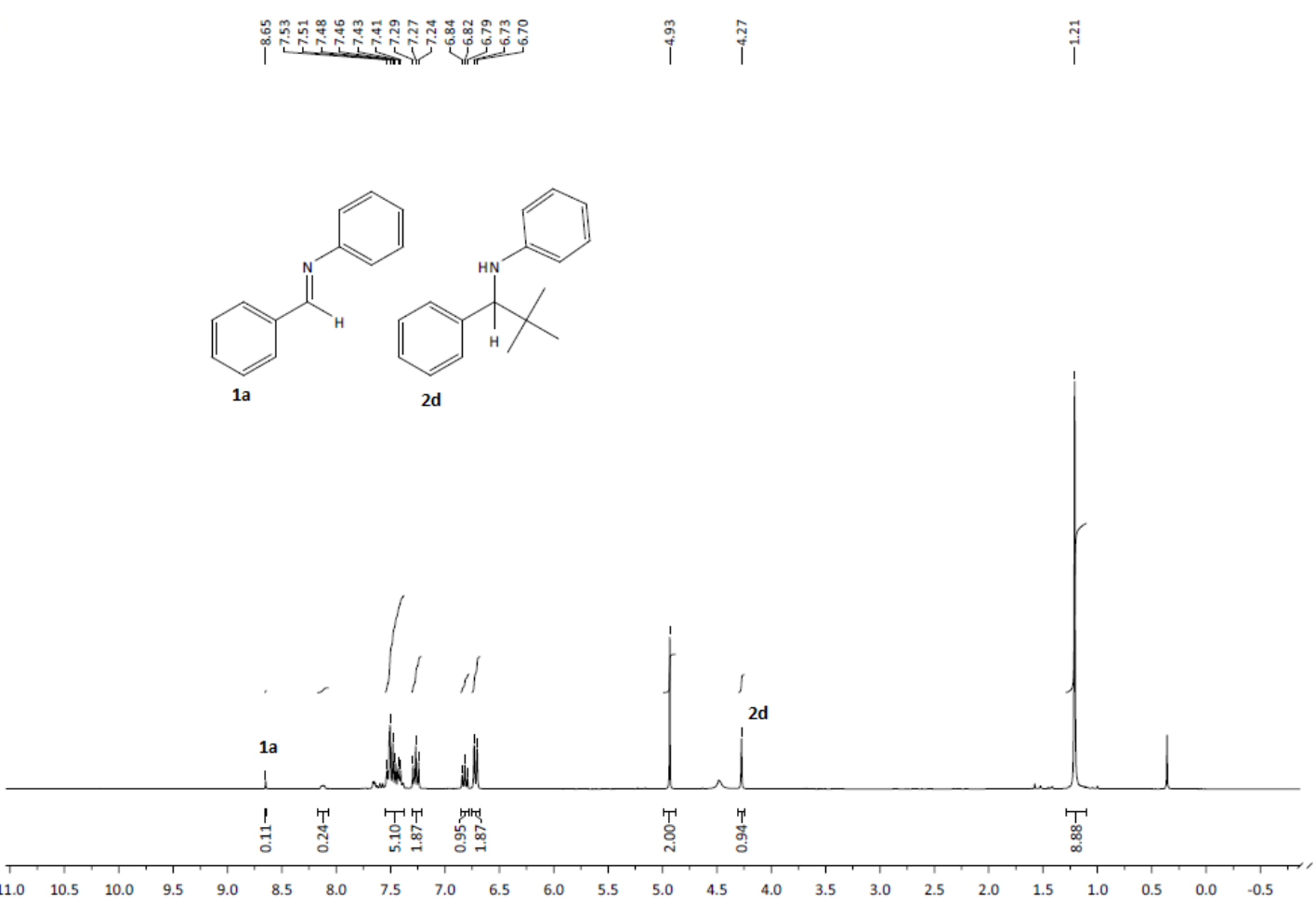

Figure ESI-4. ${ }^{1} \mathrm{H}$ NMR spectrum of the reaction crude from the addition of ${ }^{t} \mathrm{BuLi}$ to $\mathrm{N}$ benzylideneaniline (1a) in $1 \mathrm{ChCl} / 2 \mathrm{Gly}$, using $\mathrm{CH}_{2} \mathrm{Br}_{2}(4.9 \mathrm{ppm})$ as internal standard in $\mathrm{CDCl}_{3}$. 


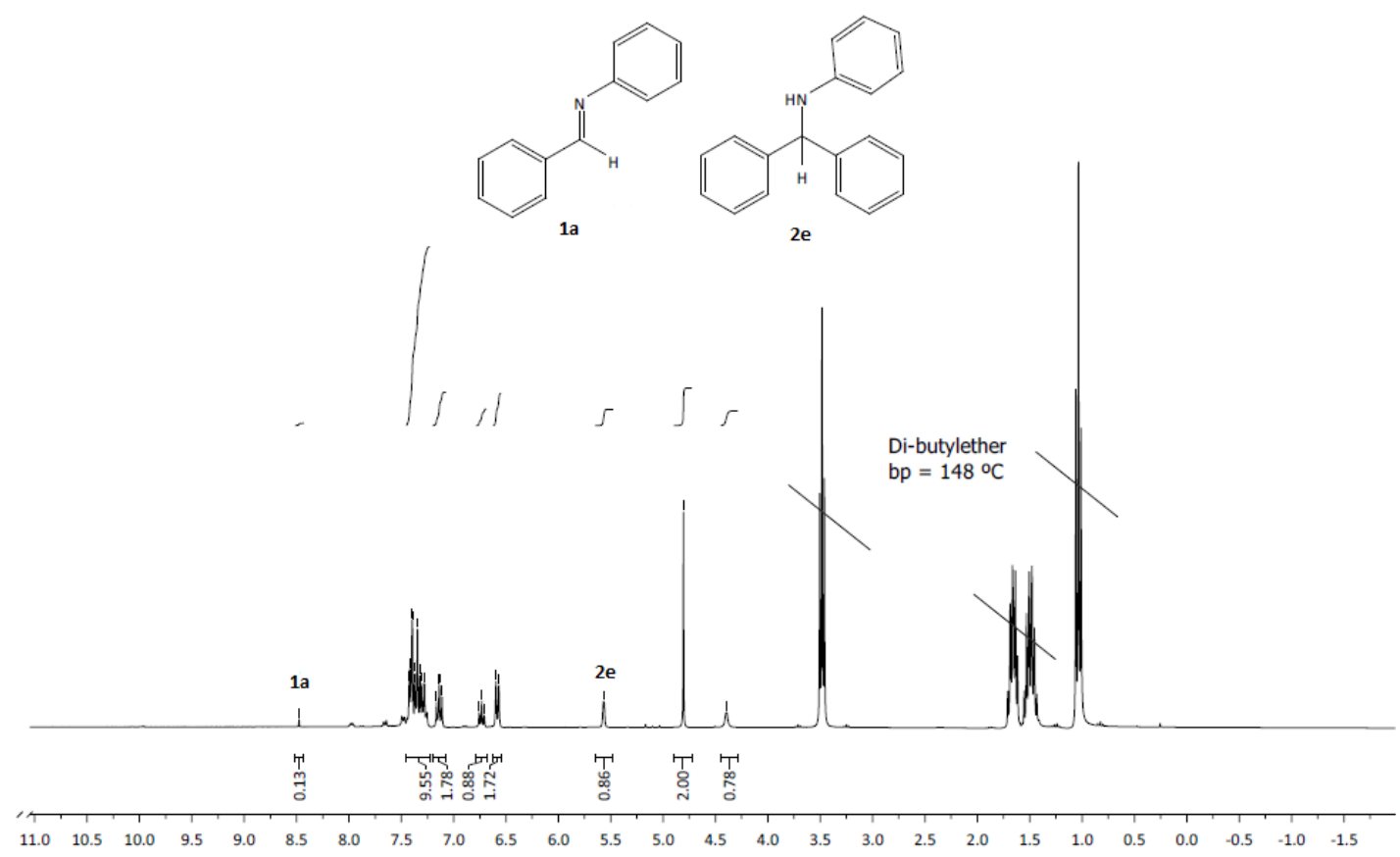

Figure ESI-5. ${ }^{1} \mathrm{H}$ NMR spectrum of the reaction crude from the addition of PhLi to $\mathrm{N}$ benzylideneaniline (1a) in $1 \mathrm{ChCl} / 2 \mathrm{Gly}$, using $\mathrm{CH}_{2} \mathrm{Br}_{2}(4.9 \mathrm{ppm})$ as internal standard in $\mathrm{CDCl}_{3}$.

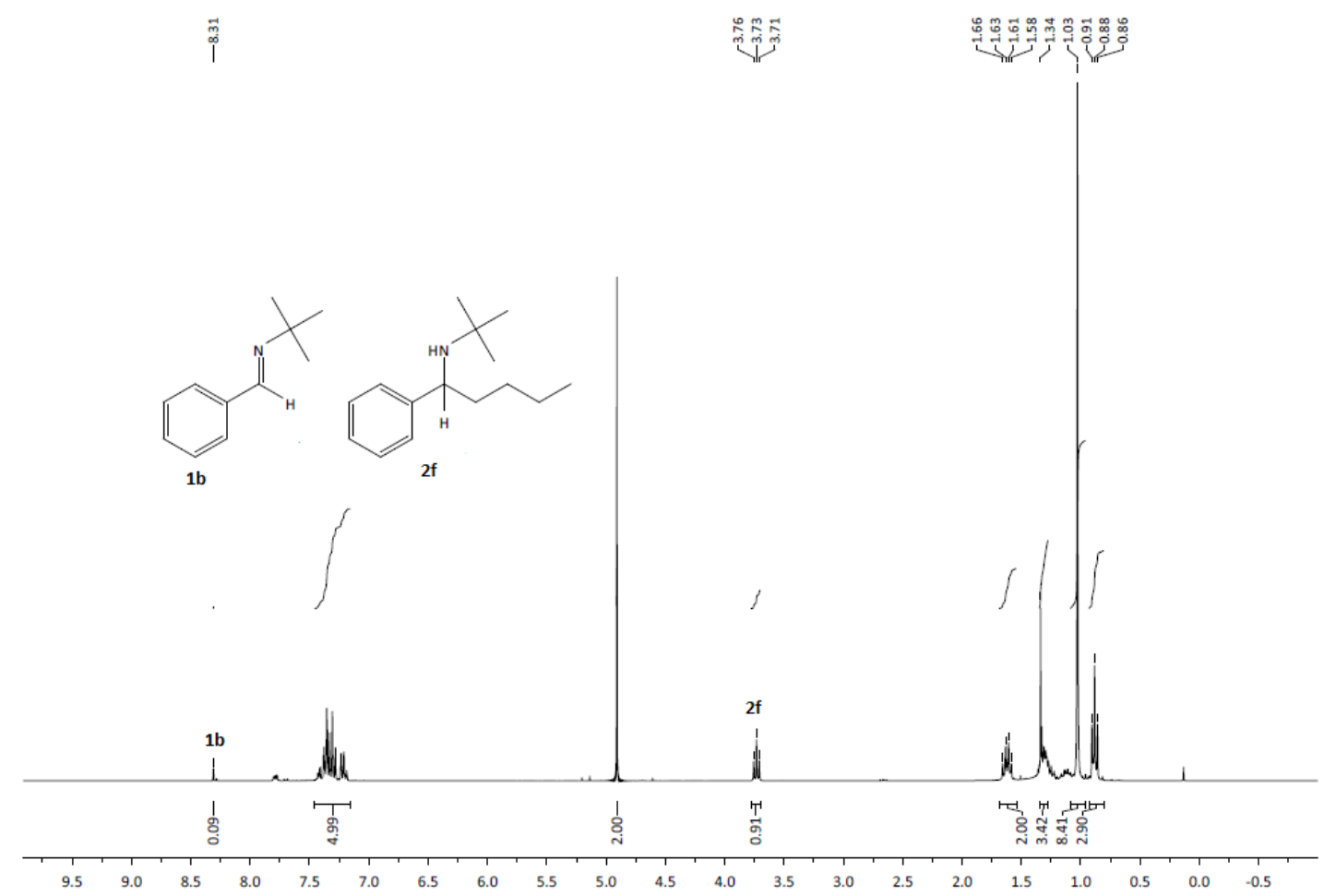

Figure ESI-6 ${ }^{1} \mathrm{H}$ NMR spectrum of the reaction crude from the addition of ${ }^{n} \mathrm{BuLi}$ to $\mathrm{N}$ benzylidene-tert-butylamine (1b) in $1 \mathrm{ChCl} / 2 \mathrm{Gly}$, using $\mathrm{CH}_{2} \mathrm{Br}_{2}(4.9 \mathrm{ppm})$ as internal standard in $\mathrm{CDCl}_{3}$. 


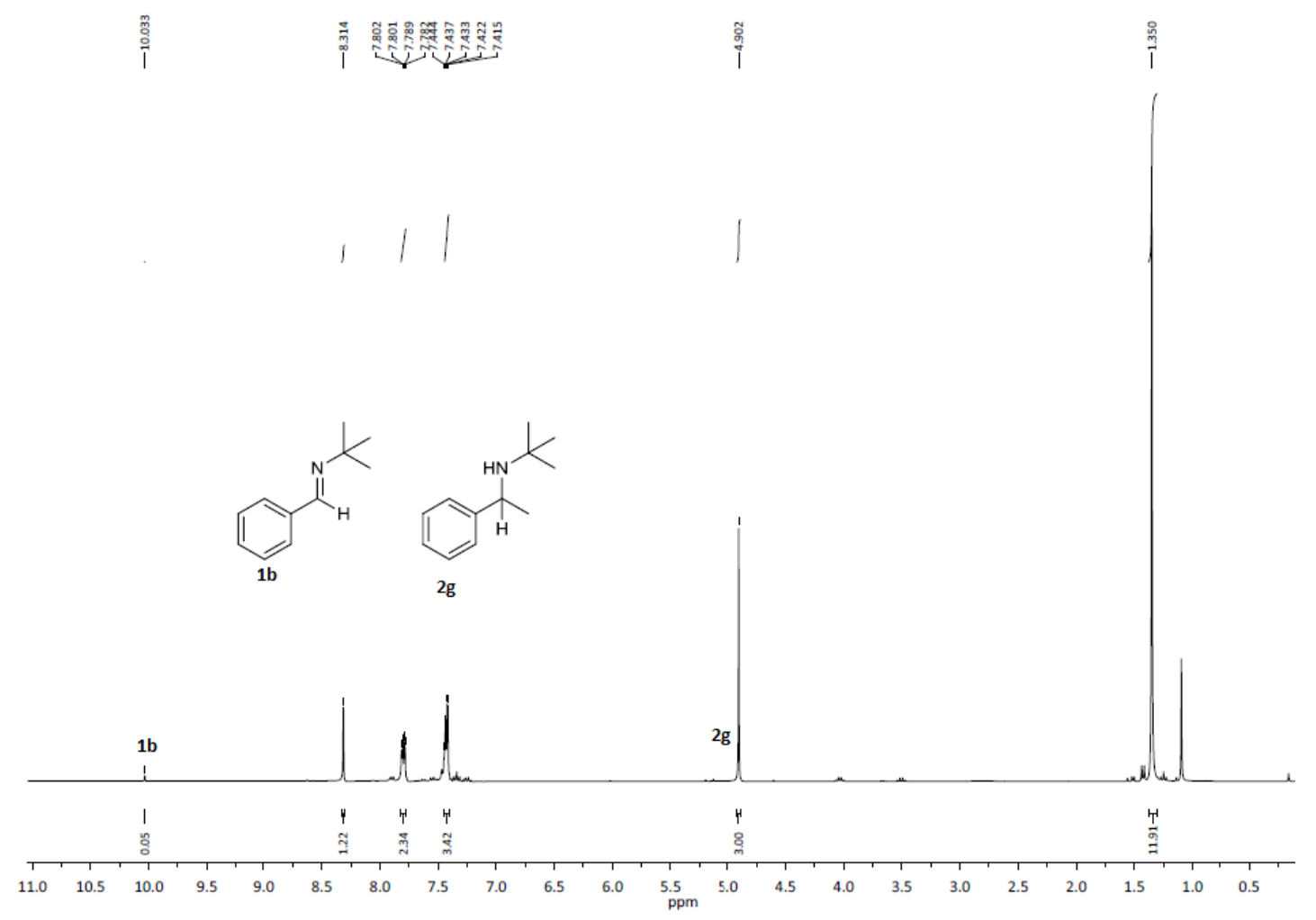

Figure ESI-7 ${ }^{1} \mathrm{H}$ NMR spectrum of the reaction crude from the addition of MeLi to $\mathrm{N}$ benzylidene-tert-butylamine (1b) in $1 C h C l / 2 G l y$, using $\mathrm{CH}_{2} \mathrm{Br}_{2}(4.9 \mathrm{ppm})$ as internal standard in $\mathrm{CDCl}_{3}$.

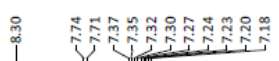
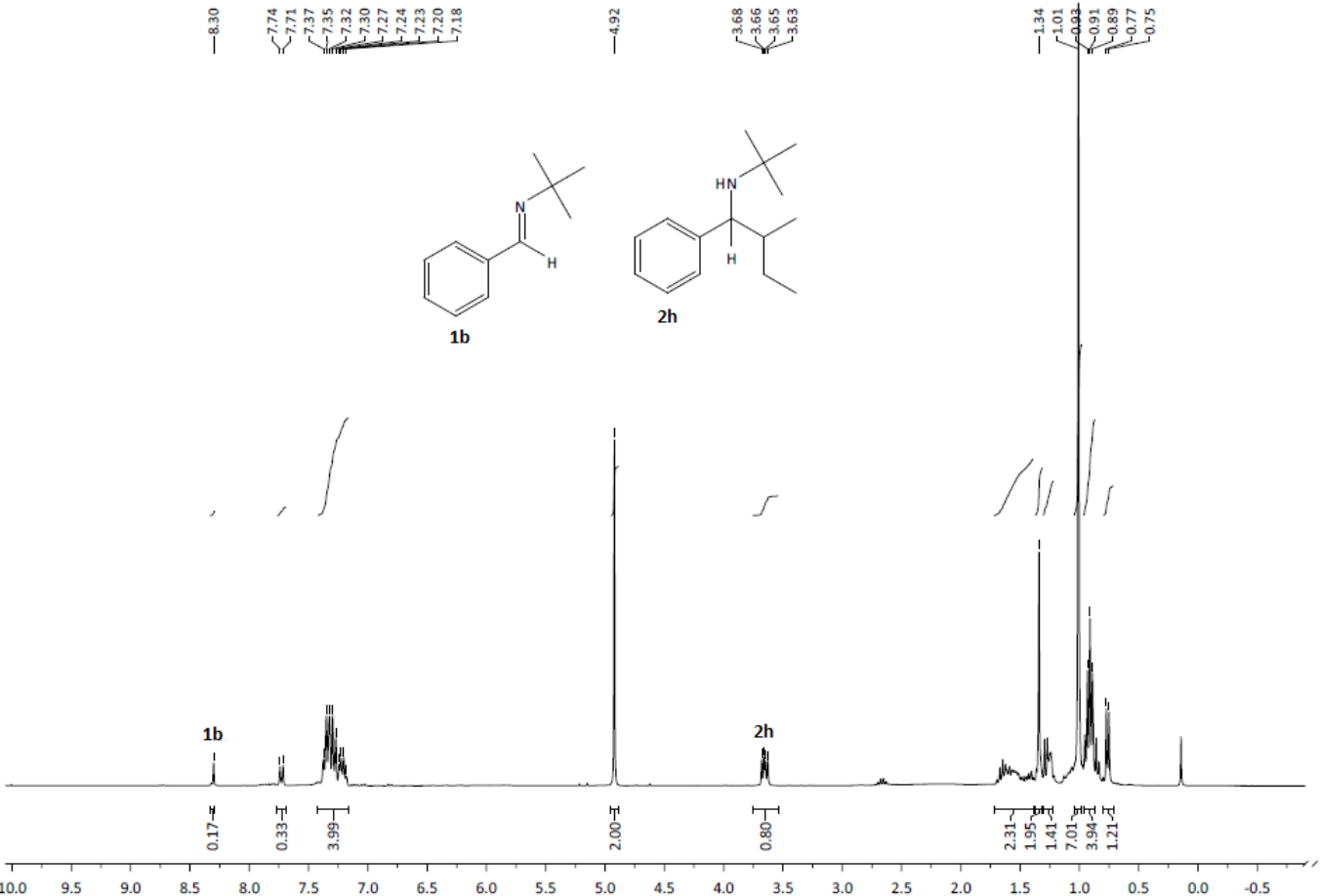

Figure ESI-8 ${ }^{1} \mathrm{H}$ NMR spectrum of the reaction crude from the addition of ${ }^{s} \mathrm{BuLi}$ to $\mathrm{N}$ benzylidene-tert-butylamine (1b) in $1 \mathrm{ChCl} / 2 \mathrm{Gly}$, using $\mathrm{CH}_{2} \mathrm{Br}_{2}(4.9 \mathrm{ppm})$ as internal standard in $\mathrm{CDCl}_{3}$. 


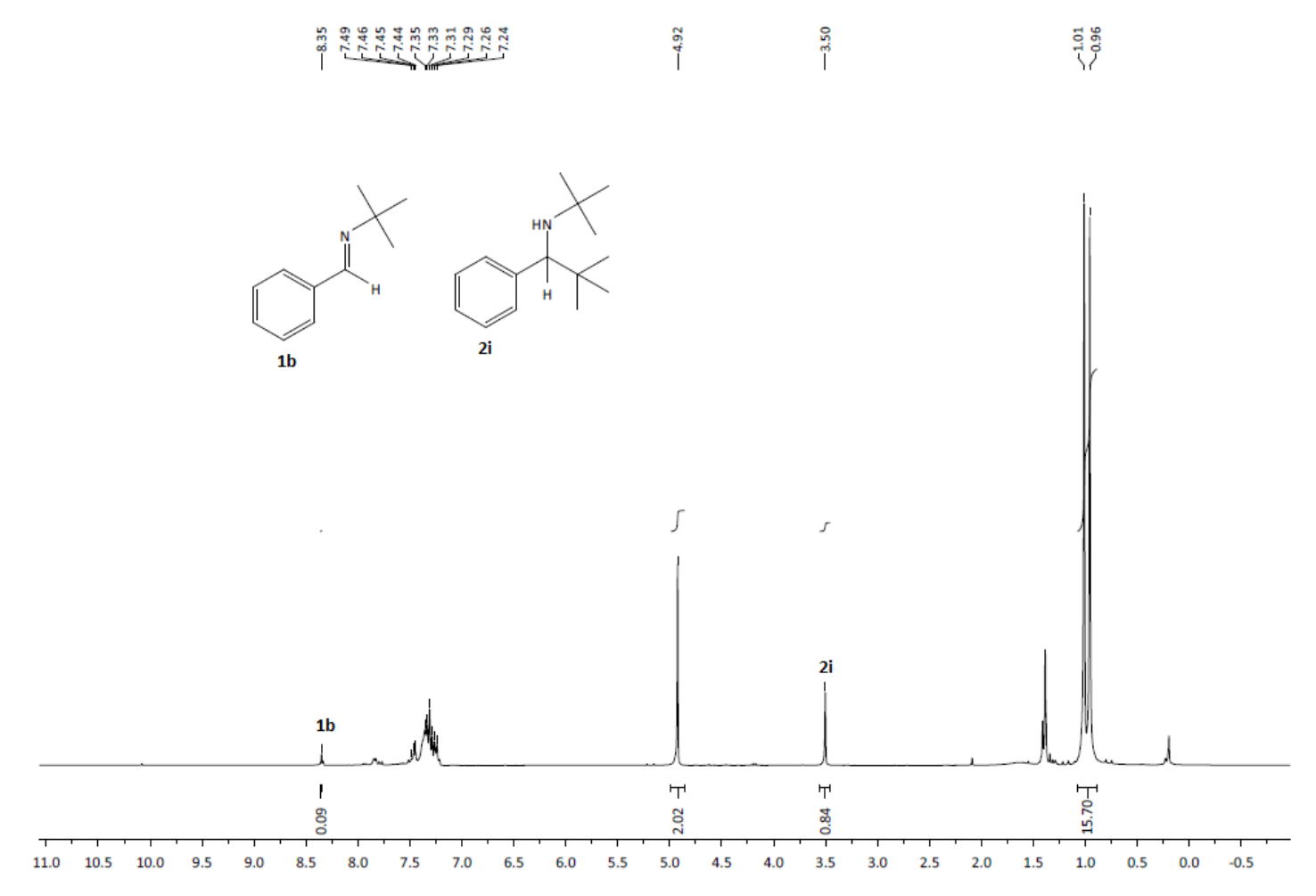

Figure ESI-9 ${ }^{1} \mathrm{H}$ NMR spectrum of the reaction crude from the addition of ${ }^{t} \mathrm{BuLi}$ to $\mathrm{N}$ benzylidene-tert-butylamine (1b) in $1 \mathrm{ChCl} / 2 \mathrm{Gly}$, using $\mathrm{CH}_{2} \mathrm{Br}_{2}(4.9 \mathrm{ppm})$ as internal standard in $\mathrm{CDCl}_{3}$.

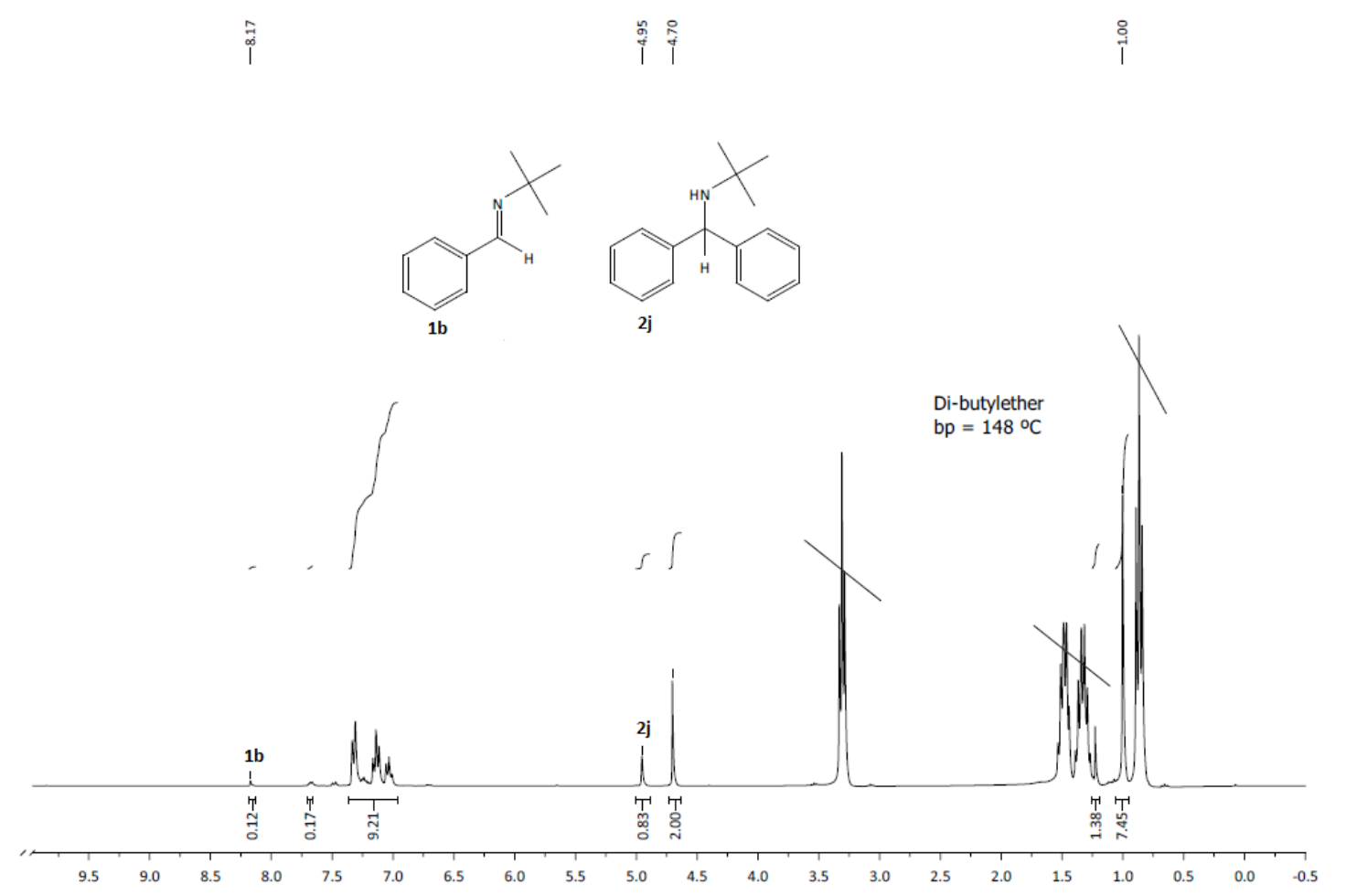

Figure ESI-10 ${ }^{1} \mathrm{H}$ NMR spectrum of the reaction crude from the addition of $\mathrm{PhLi}$ to $\mathrm{N}$ benzylidene-tert-butylamine (1b) in $1 \mathrm{ChCl} / 2 \mathrm{Gly}$, using $\mathrm{CH}_{2} \mathrm{Br}_{2}(4.9 \mathrm{ppm})$ as internal standard in $\mathrm{CDCl}_{3}$. 


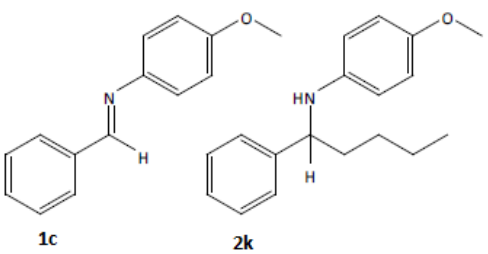

$2 \mathbf{k}$

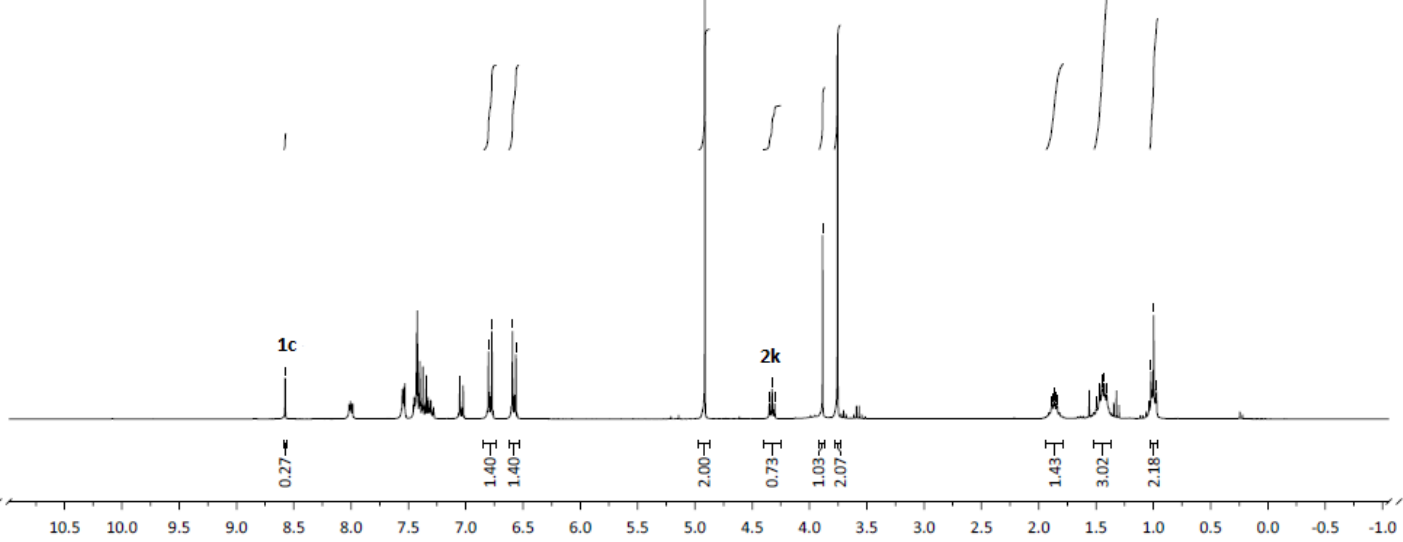

Figure ESI-11 ${ }^{1} \mathrm{H}$ NMR spectrum of the reaction crude from the addition of ${ }^{n} \mathrm{BuLi}$ to $\mathrm{N}$ benzylidene-4-methoxyaniline (1c) in $1 \mathrm{ChCl} / 2 \mathrm{Gly}$, using $\mathrm{CH}_{2} \mathrm{Br}_{2}(4.9 \mathrm{ppm})$ as internal standard in $\mathrm{CDCl}_{3}$.
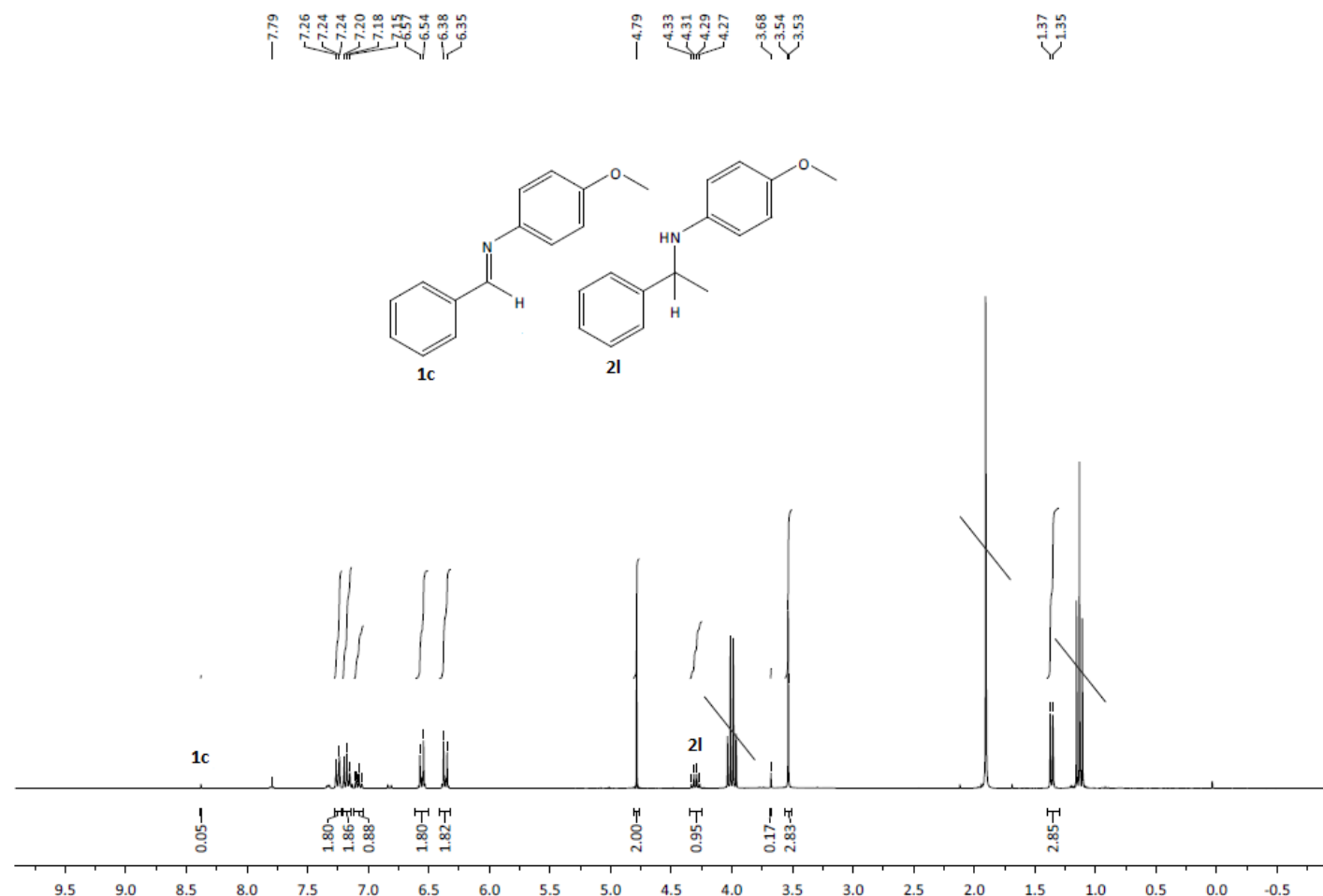

Figure ESI-12 ${ }^{1} \mathrm{H}$ NMR spectrum of the reaction crude from the addition of MeLi to $\mathrm{N}$ benzylidene-4-methoxyaniline (1c) in $1 \mathrm{ChCl} / 2 \mathrm{Gly}$, using $\mathrm{CH}_{2} \mathrm{Br}_{2}(4.9 \mathrm{ppm})$ as internal standard in $\mathrm{CDCl}_{3}$. 


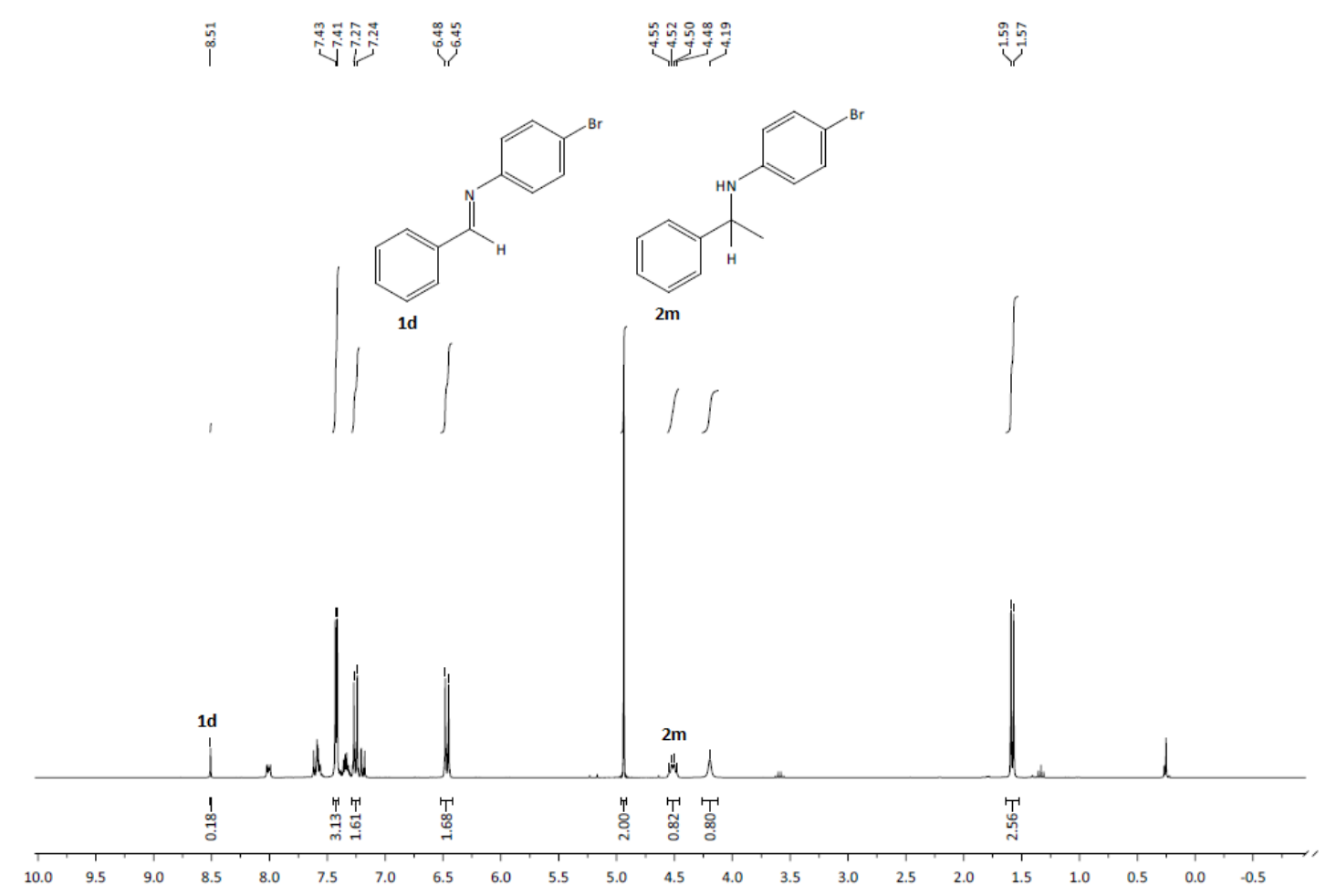

Figure ESI-13 ${ }^{1} \mathrm{H}$ NMR spectrum of the reaction crude from the addition of MeLi to $\mathrm{N}$ benzylidene-4-bromoaniline (1d) in $1 \mathrm{ChCl} / 2 \mathrm{Gly}$, using $\mathrm{CH}_{2} \mathrm{Br}_{2}(4.9 \mathrm{ppm}$ ) as internal standard in $\mathrm{CDCl}_{3}$.
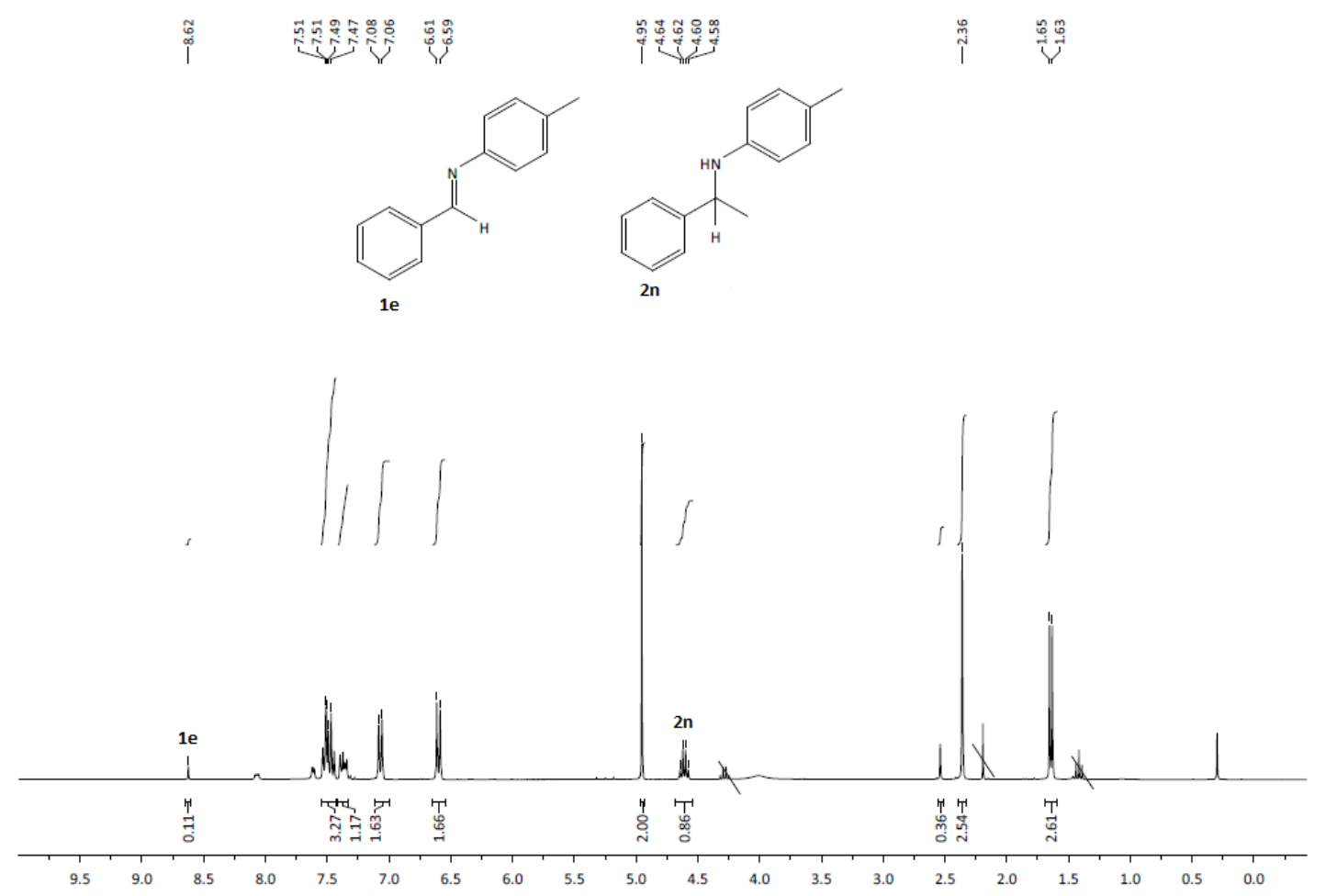

Figure ESI-14 ${ }^{1} \mathrm{H}$ NMR spectrum of the reaction crude from the addition of MeLi to $\mathrm{N}$ benzylidene-4-methylaniline (1e) in $1 \mathrm{ChCl} / 2 \mathrm{Gly}$, using $\mathrm{CH}_{2} \mathrm{Br}_{2}(4.9 \mathrm{ppm})$ as internal standard in $\mathrm{CDCl}_{3}$. 


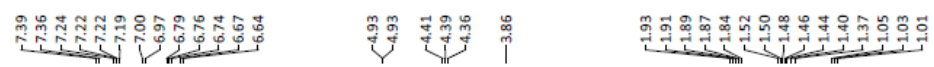

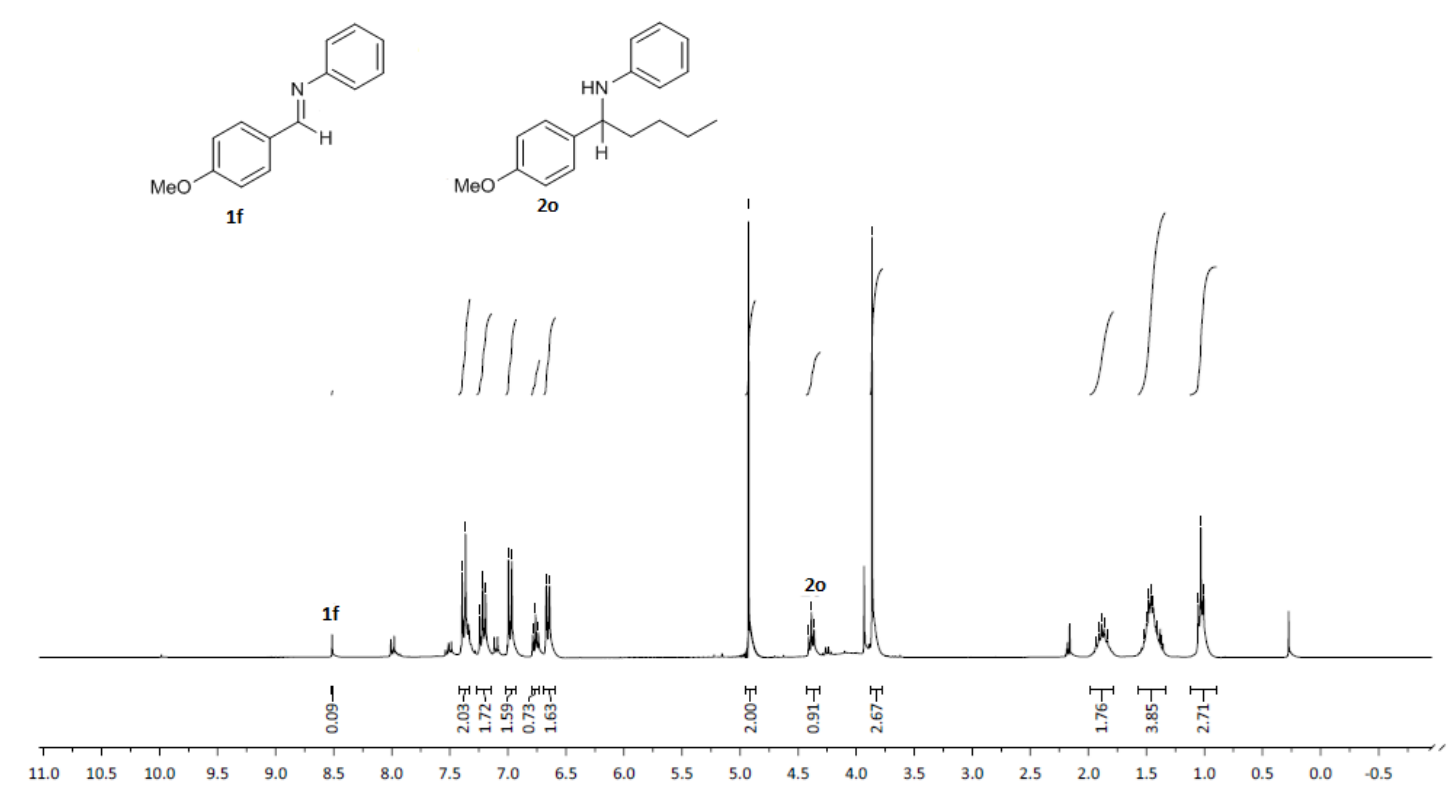

Figure ESI-15 ${ }^{1} \mathrm{H}$ NMR spectrum of the reaction crude from the addition of ${ }^{n} \mathrm{BuLi}$ to $\mathrm{N}$ (4-methoxybenzylidene)aniline (1f) in $1 \mathrm{ChCl} / 2 \mathrm{Gly}$, using $\mathrm{CH}_{2} \mathrm{Br}_{2}(4.9 \mathrm{ppm}$ ) as internal standard in $\mathrm{CDCl}_{3}$.
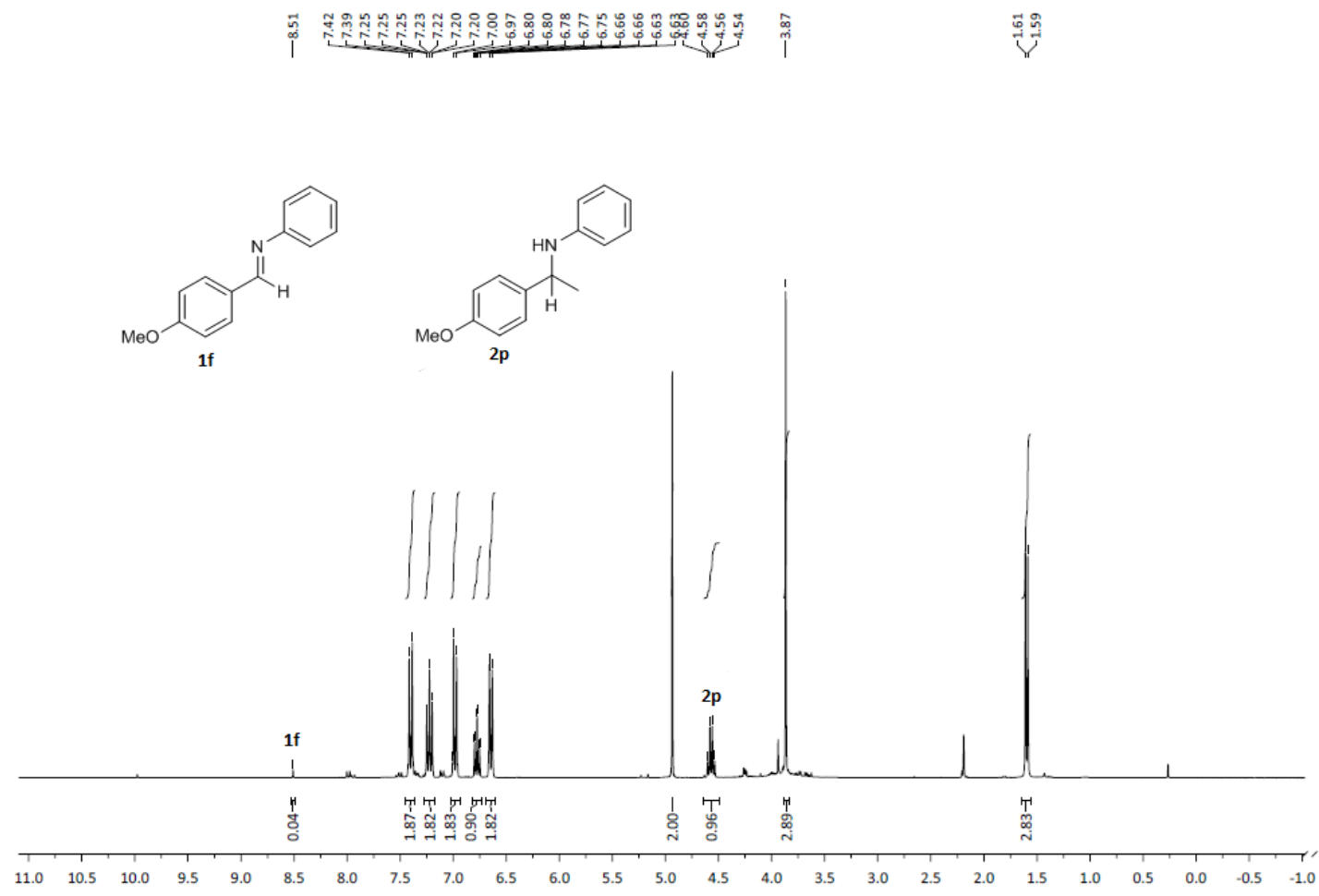

Figure ESI-16 ${ }^{1} \mathrm{H}$ NMR spectrum of the reaction crude from the addition of MeLi to $\mathrm{N}$ (4-methoxybenzylidene)aniline (1f) in $1 \mathrm{ChCl} / 2 \mathrm{Gly}$, using $\mathrm{CH}_{2} \mathrm{Br}_{2}(4.9 \mathrm{ppm})$ as internal standard in $\mathrm{CDCl}_{3}$. 


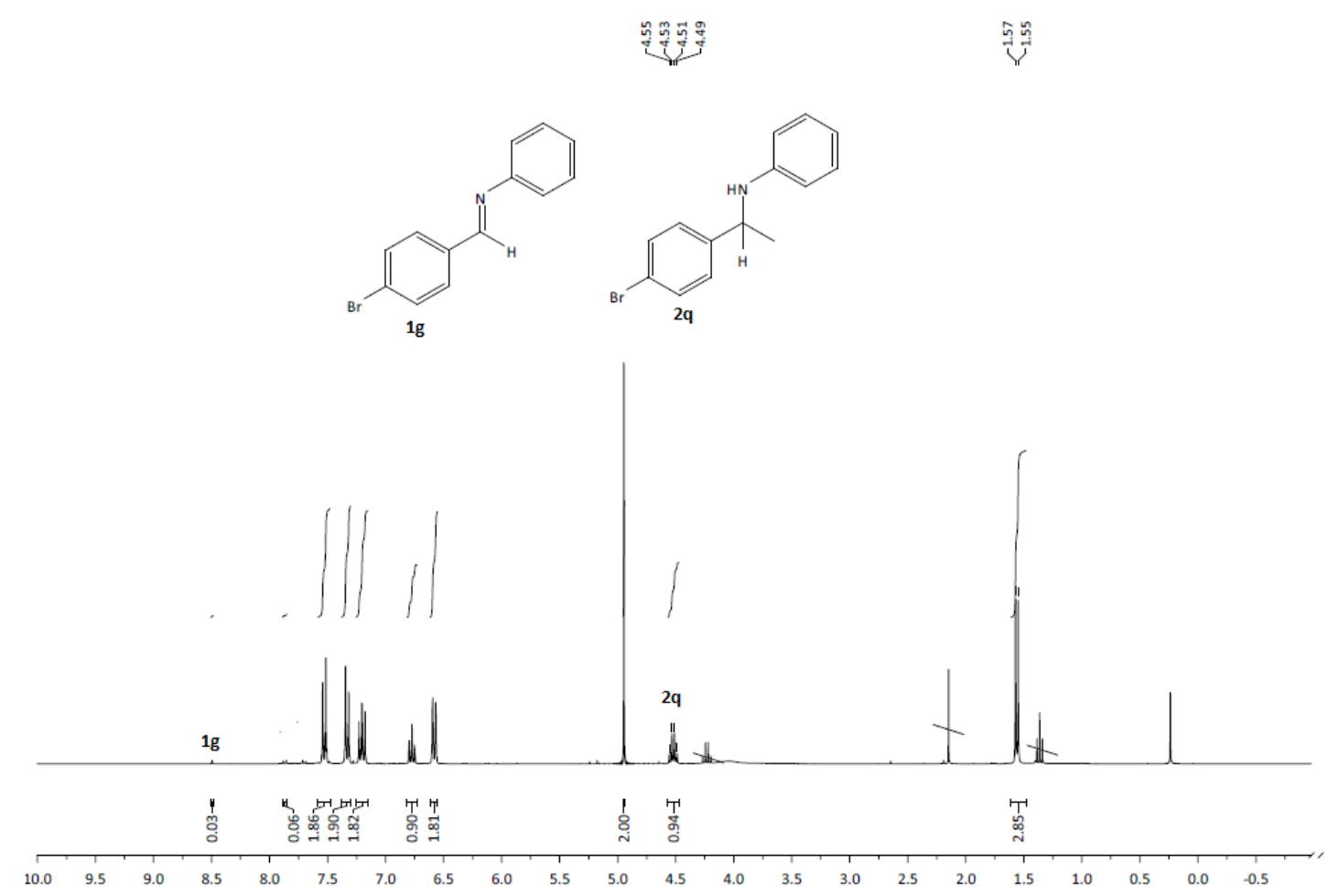

Figure ESI-17 ${ }^{1} \mathrm{H}$ NMR spectrum of the reaction crude from the addition of MeLi to $\mathrm{N}$ (4-bromobenzylidene)aniline (1g) in $1 \mathrm{ChCl} / 2 \mathrm{Gly}$, using $\mathrm{CH}_{2} \mathrm{Br}_{2}(4.9 \mathrm{ppm}$ ) as internal standard in $\mathrm{CDCl}_{3}$.

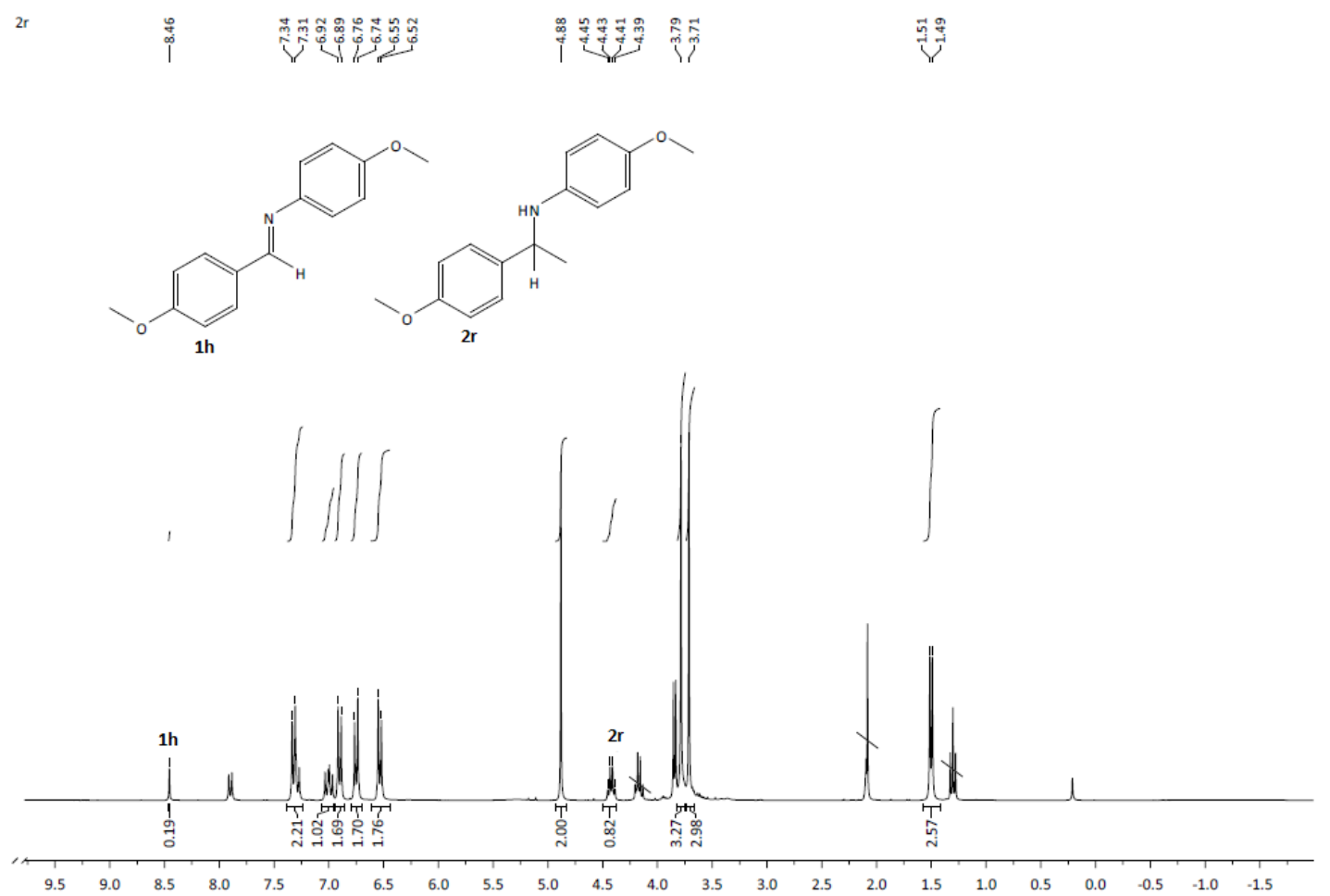

Figure ESI-18 ${ }^{1} \mathrm{H}$ NMR spectrum of the reaction crude from the addition of MeLi to 4methoxy- $N$-(4-methoxybenzylidene)aniline (1h) in $1 \mathrm{ChCl} / 2 \mathrm{Gly}$, using $\mathrm{CH}_{2} \mathrm{Br}_{2}$ (4.9 ppm) as internal standard in $\mathrm{CDCl}_{3}$. 


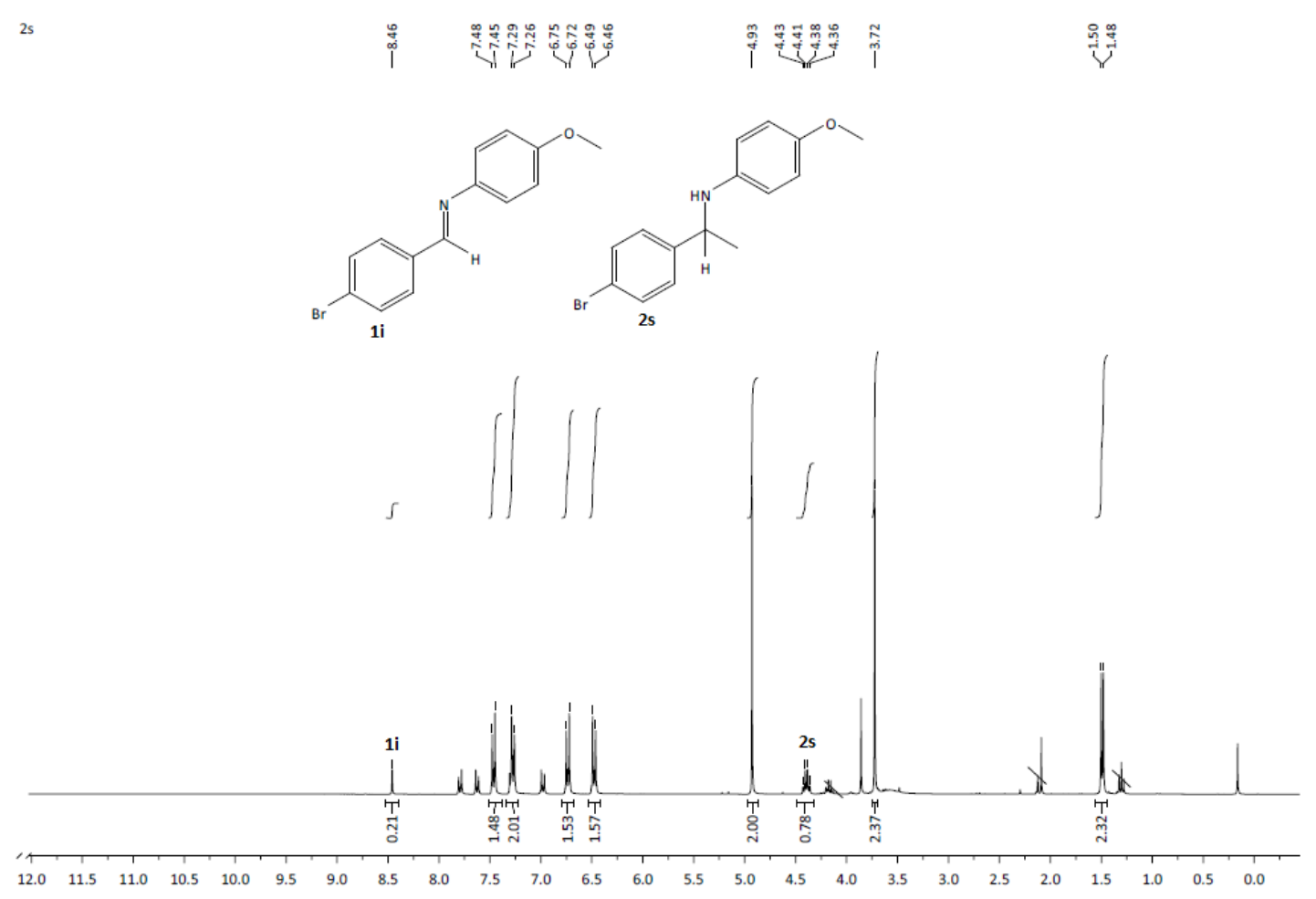

Figure ESI-19 ${ }^{1} \mathrm{H}$ NMR spectrum of the reaction crude from the addition of MeLi to $\mathrm{N}$ (4-bromobenzylidene)-4-methoxyaniline (1i) in $1 \mathrm{ChCl} / 2 \mathrm{Gly}$, using $\mathrm{CH}_{2} \mathrm{Br}_{2}$ (4.9 ppm) as internal standard in $\mathrm{CDCl}_{3}$.

\section{General procedure for addition reactions of RLi reagents with quinolines in DESs.}

Syntheses were performed under air and at room temperature. In a glass tube, the appropriate quinoline $(1 \mathrm{mmol})$ was dissolved in the corresponding Deep Eutectic Solvent $(D E S, 1 \mathrm{~g})$ under air, followed by the addition of the organolithium reagent (RLi, $1.4 \mathrm{mmol}$ ) at room temperature, and the reaction mixture was stirred for 5 seconds. Addition of saturated solution of Rochelle salt to the reaction crude allows the straightforward separation of the desired organic product, as described for amines 2a-s. Yields were determined by ${ }^{1} \mathrm{H}$ NMR methodology using dibromomethane as internal standard. C2-substituted dihydroquinolines 6a-d are known compounds and their ${ }^{1} \mathrm{H}$ NMR data matched with that reported in the literature. ${ }^{8}$ 


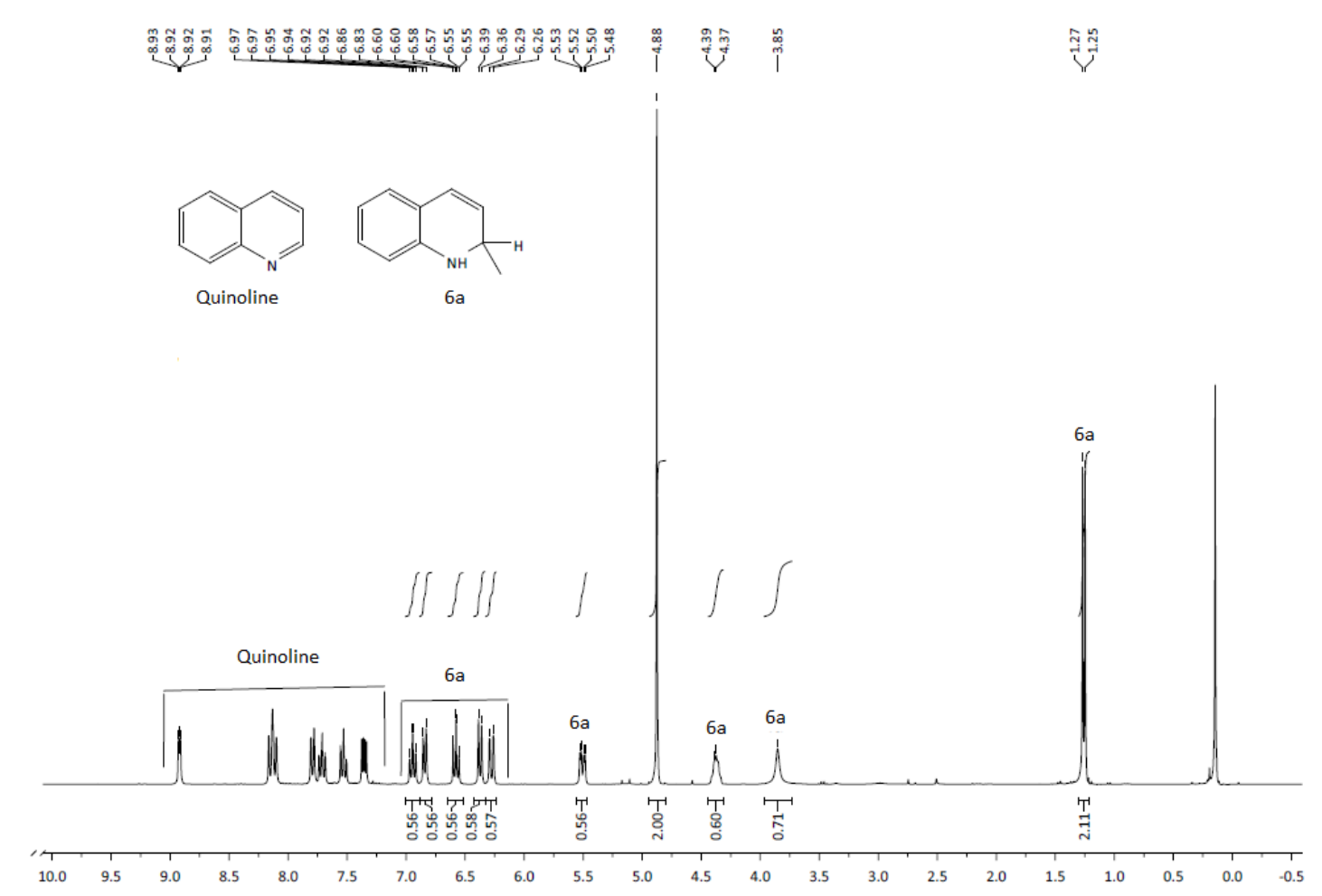

Figure ESI-20. ${ }^{1} \mathrm{H}$ NMR spectrum of the reaction crude from the addition of MeLi to quinoline in $1 \mathrm{ChCl} / 2 \mathrm{Gly}$, using $\mathrm{CH}_{2} \mathrm{Br}_{2}(4.9 \mathrm{ppm})$ as internal standard in $\mathrm{CDCl}_{3}$.
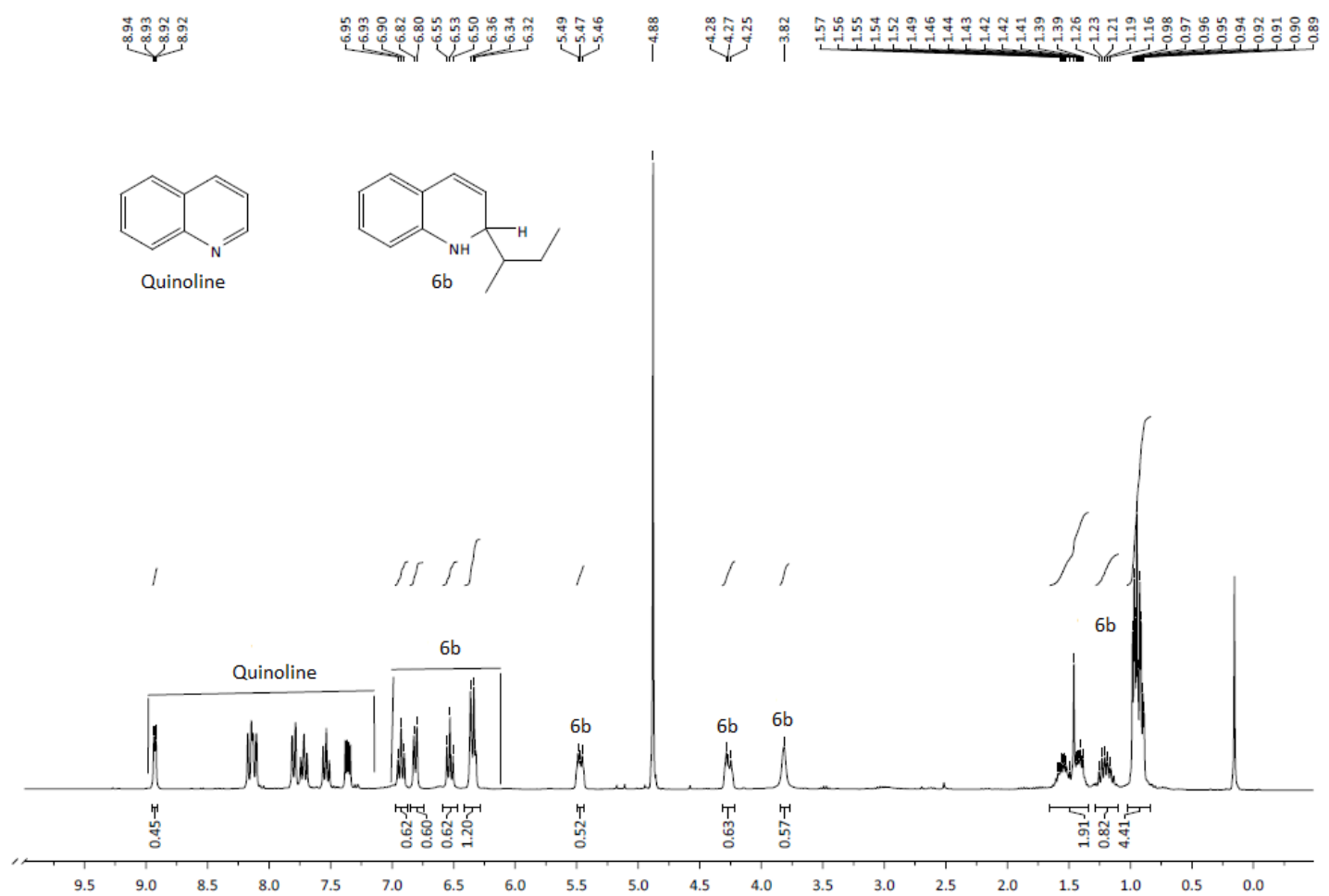

Figure ESI-21 ${ }^{1} \mathrm{H}$ NMR spectrum of the reaction crude from the addition of ${ }^{s} \mathrm{BuLi}$ to quinoline in $1 \mathrm{ChCl} / 2 \mathrm{Gly}$, using $\mathrm{CH}_{2} \mathrm{Br}_{2}(4.9 \mathrm{ppm})$ as internal standard in $\mathrm{CDCl}_{3}$. 


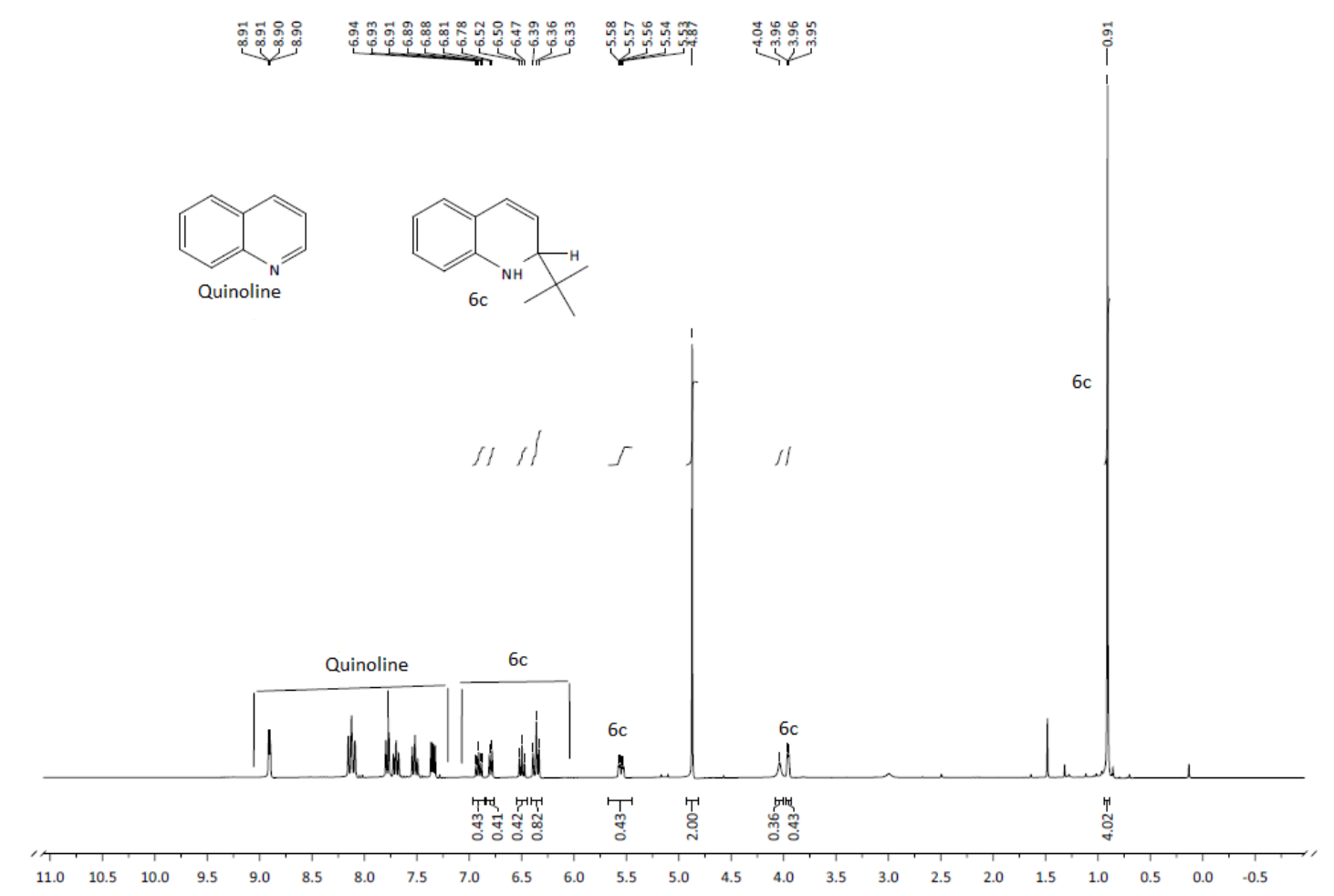

Figure ESI-22. ${ }^{1} \mathrm{H}$ NMR spectrum of the reaction crude from the addition of ${ }^{t} \mathrm{BuLi}$ to quinoline in $1 \mathrm{ChCl} / 2 \mathrm{Gly}$, using $\mathrm{CH}_{2} \mathrm{Br}_{2}(4.9 \mathrm{ppm})$ as internal standard in $\mathrm{CDCl}_{3}$.

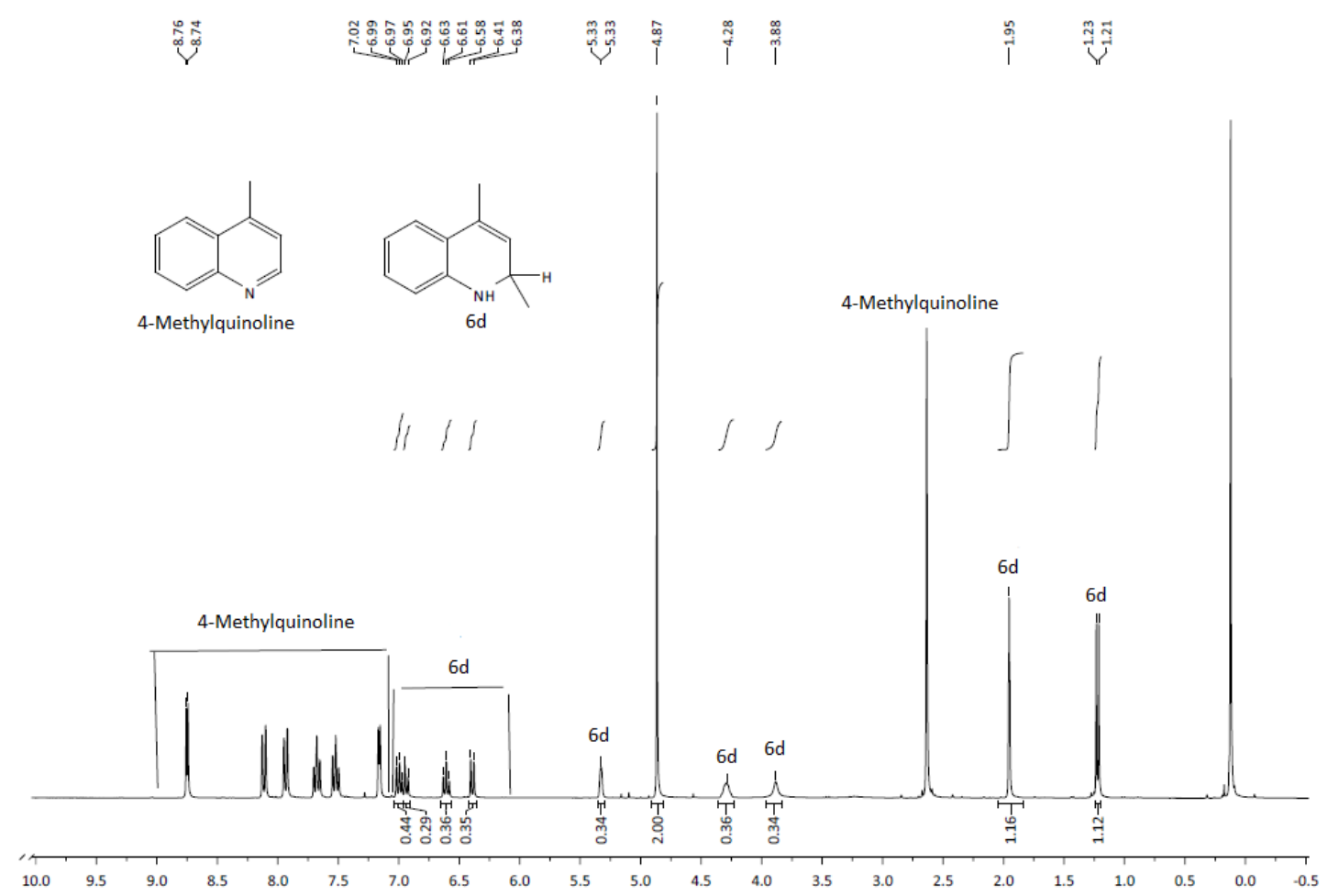

Figure ESI-23. ${ }^{1} \mathrm{H}$ NMR spectrum of the reaction crude from the addition of MeLi to 4methylquinoline in $1 \mathrm{ChCl} / 2 \mathrm{Gly}$, using $\mathrm{CH}_{2} \mathrm{Br}_{2}(4.9 \mathrm{ppm})$ as internal standard in $\mathrm{CDCl}_{3}$. 


\section{Synthesis and X-Ray Crystal Structure Determination of Compound 3}

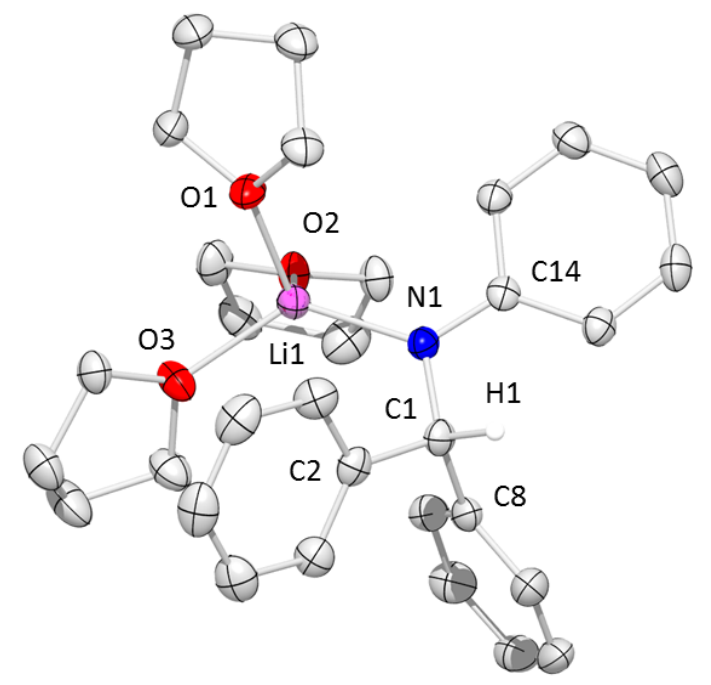

Figure ESI-24. Solid state structure of compound 3 with thermal ellipsoids at $50 \%$ of probability. Hydrogen atoms except that one attached to $\mathrm{C} 1$ are omitted for clarity. Selected bond distances $(\AA)$ and angles ( $\left.{ }^{\circ}\right)$ Li1-O1 1.969(2), Li1-O2 2.028(3), Li1-O3 1.988(3), Li1-N1 2.004(2), N1-C1 1.4569(17); O1-Li1-O2 111.56(12), O1-Li1-O3 100.90(11), O1-Li1-N1 111.82(12), O2-Li1-O3 93.89(10), O2-Li1-N1 109.93(11), O3-Li1-N1 127.22(13), C1-N1-C14 114.80(10), C1-N1-Li1 121.48(11), C14-N1-Li1 123.04(11). 
Table ESI-1. Selected crystallographic and refinement parameters.

\begin{tabular}{|c|c|}
\hline & 3 \\
\hline Empirical formula & $\mathrm{C}_{31} \mathrm{H}_{40} \mathrm{LiNO}_{3}$ \\
\hline Molecular Weight & 481.58 \\
\hline Temperature $(\mathrm{K})$ & $123(2)$ \\
\hline Wavelength $(\AA)$ & 0.71073 \\
\hline Crystal system, & monoclinic \\
\hline Space group & $\mathrm{P} 2 / \mathrm{c}$ \\
\hline$a(\AA)$ & $18.0621(5)$ \\
\hline$b(\AA)$ & $14.3719(5)$ \\
\hline$c(\AA)$ & $10.4884(3)$ \\
\hline$\beta\left(^{\circ}\right)$ & $97.603(3)$ \\
\hline Cell volume $\left(\AA^{3}\right)$ & 2698.71(14) \\
\hline $\mathrm{Z}$ & 4 \\
\hline$\rho_{\text {calc }}\left({\left.\mathrm{g} . \mathrm{cm}^{-3}\right)}^{-3}\right.$ & 1.185 \\
\hline$\mu\left(\mathrm{mm}^{-1}\right)$ & 0.074 \\
\hline $2 \theta \max \left({ }^{\circ}\right)$ & 58.95 \\
\hline Index ranges & $\begin{array}{l}-23 \leq h \leq 23 \\
-15 \leq k \leq 19 \\
-14 \leq l \leq 14\end{array}$ \\
\hline Reflections collected & 16800 \\
\hline Reflections unique & 6901 \\
\hline Reflections obs. & 5113 \\
\hline$R_{\text {int }}$ & 0.0325 \\
\hline No. Parameters & 325 \\
\hline Goodness-of-fit-on $F^{2}(\mathrm{GOF})$ & 1.024 \\
\hline Final $R$ indices $[\triangle 2 \sigma(I)]$ & 0.0524 \\
\hline$R$ indices (all data) & 0.1174 \\
\hline Largest diff. peak and hole $\left(\mathrm{e} \AA^{-3}\right)$ & 0.244 and -0.197 \\
\hline
\end{tabular}

\section{Synthesis of $\left[(\mathrm{THF})_{3} \mathrm{LiN}(\mathrm{Ph})\left(\mathrm{CHPh}_{2}\right)\right](3)$}

To a THF (10 mL) solution of $N$-benzylideneaniline 1a (1 mmol, 0.181g), LiPh (1 mmol, $0.084 \mathrm{~g}$ ) was added. After $30 \mathrm{~min}$ stirring at room temperature the volume of the pale yellow solution was reduced under vacuum to $1 \mathrm{~mL}$ of THF. Then $2 \mathrm{~mL}$ of hexane was introduced, and the solution was stored at $-30{ }^{\circ} \mathrm{C}$ overnight, affording colorless crystals of compound 3 (0.32 g, 66\%). ${ }^{1} \mathrm{H}$ NMR (400 MHz, $298 \mathrm{~K}, \mathrm{~d}_{8}$-THF) $\delta(\mathrm{ppm})=1.77(\mathrm{~m}, 4 \mathrm{H}, \mathrm{THF}), 3.61(\mathrm{~m}, 4 \mathrm{H}, \mathrm{THF}), 5.25\left(\mathrm{~s}, 1 \mathrm{H}, \mathrm{C} H \mathrm{Ph}_{2}\right), 5.73(\mathrm{t}, J=7.2$ $\mathrm{Hz}, 1 \mathrm{H}$, para- $\mathrm{CH}, \mathrm{N} P h), 5.98$ (broad d, 2H, ortho- $\mathrm{CH}, \mathrm{N} P h), 6.6$ (t, $J=7.2 \mathrm{~Hz}, 2 \mathrm{H}$, meta-CH, NPh), 7.03 (t, $J=7.2 \mathrm{~Hz}, 2 \mathrm{H}$, para-CH, CHPh $), 7.14(\mathrm{t}, J=7.2 \mathrm{~Hz}, 4 \mathrm{H}$, meta-CH, CHPh $), 7.28$ (d, J=7.2 Hz, 4H, ortho- $\left.\mathrm{CH}, \mathrm{CHPh} h_{2}\right) .{ }^{13} \mathrm{C} \mathrm{NMR}(100 \mathrm{MHz}$, $\left.298 \mathrm{~K}, \mathrm{C}_{6} \mathrm{D}_{6}\right) \delta(\mathrm{ppm})=26.1(\mathrm{THF}), 68.0(\mathrm{THF}), 68.2\left(\mathrm{CHPh}_{2}\right), 106.6($ para $-\mathrm{CH}$, $\mathrm{NPh}$ ), 113.7 (broad, ortho- $\mathrm{CH}, \mathrm{NPh}$ ), 125.6 (para- $\mathrm{CH}, \mathrm{CH} \mathrm{Ph}_{2}$ ), 128.2 (meta- $\mathrm{CH}$, 
$\mathrm{CHPh}$ ), 128.7 (meta-CH, NPh) 128.8 (ortho- $\mathrm{CH}, \mathrm{CHPh}$ ), 150.4 (ipso-C, $\mathrm{CH} P h_{2}$ ), 161.5 (ipso-C, NPh). ${ }^{7} \mathrm{Li} \mathrm{NMR}\left(155.47 \mathrm{MHz}, 298 \mathrm{~K}, \mathrm{C}_{6} \mathrm{D}_{6}\right) \delta(\mathrm{ppm})=0.65$. Anal Calcd for $\mathrm{C}_{31} \mathrm{H}_{40} \mathrm{LiNO}_{3}$ : C, 77.31; H, 8.37; N, 2.91. Found, C, 78.03; H, 7.92; N, 2.73.
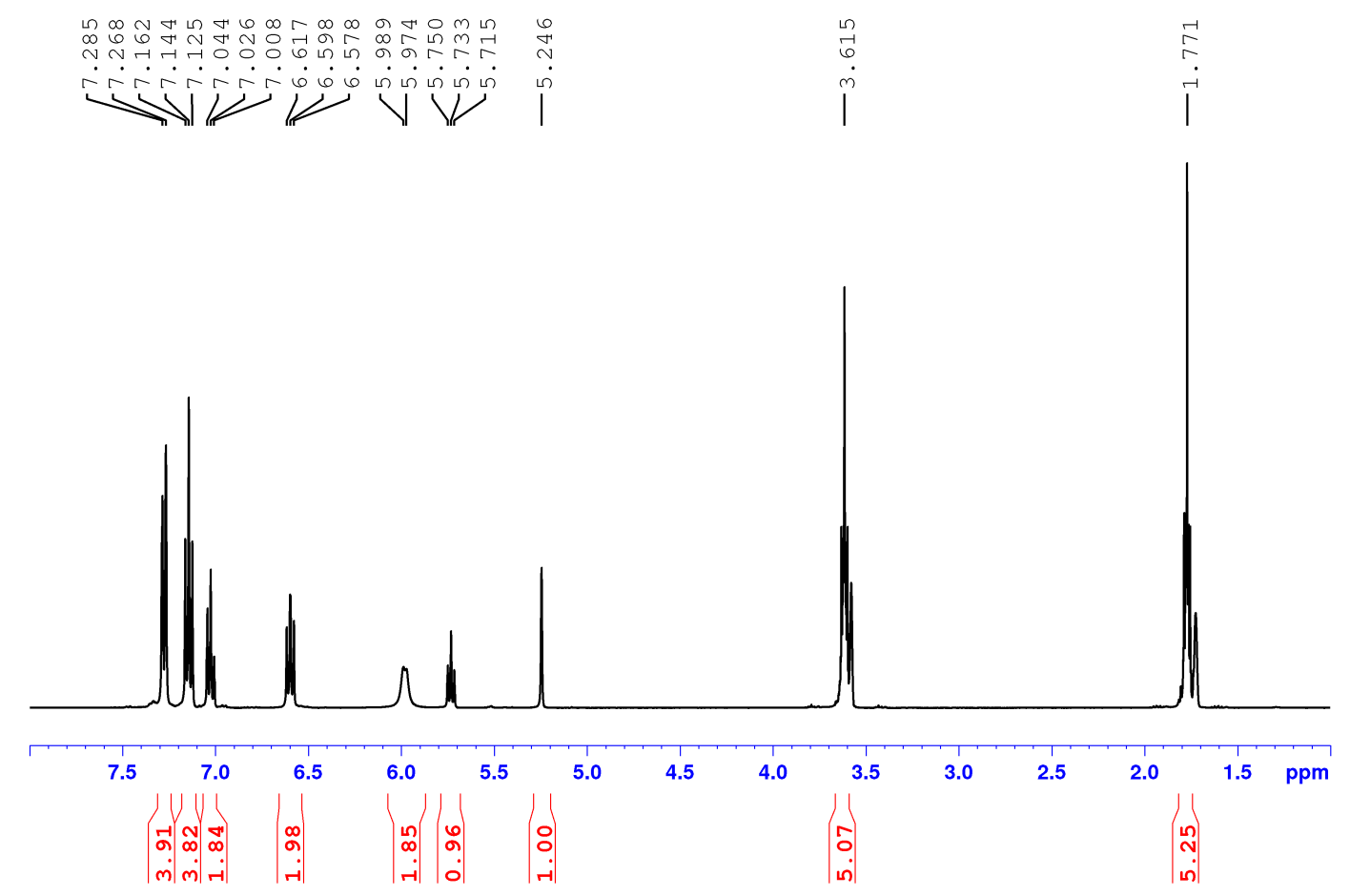

Figure ESI-25. ${ }^{1} \mathrm{H}$ NMR spectrum of compound 3 in $\mathrm{d}_{8}$-THF at $298 \mathrm{~K}$.

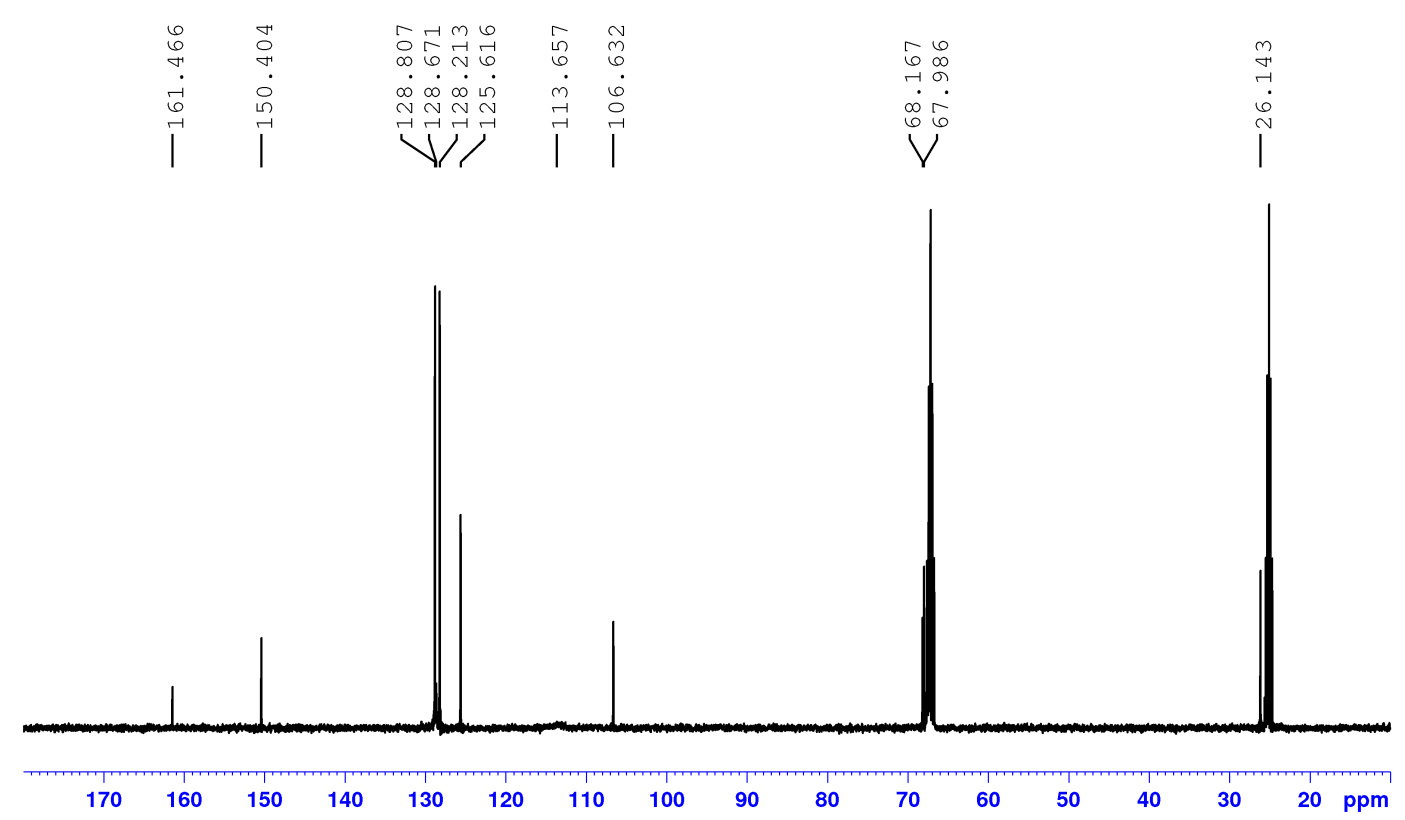

Figure ESI-26. ${ }^{13} \mathrm{C}$ NMR spectrum of compound 3 in $\mathrm{d}_{8}$-THF at $298 \mathrm{~K}$. 


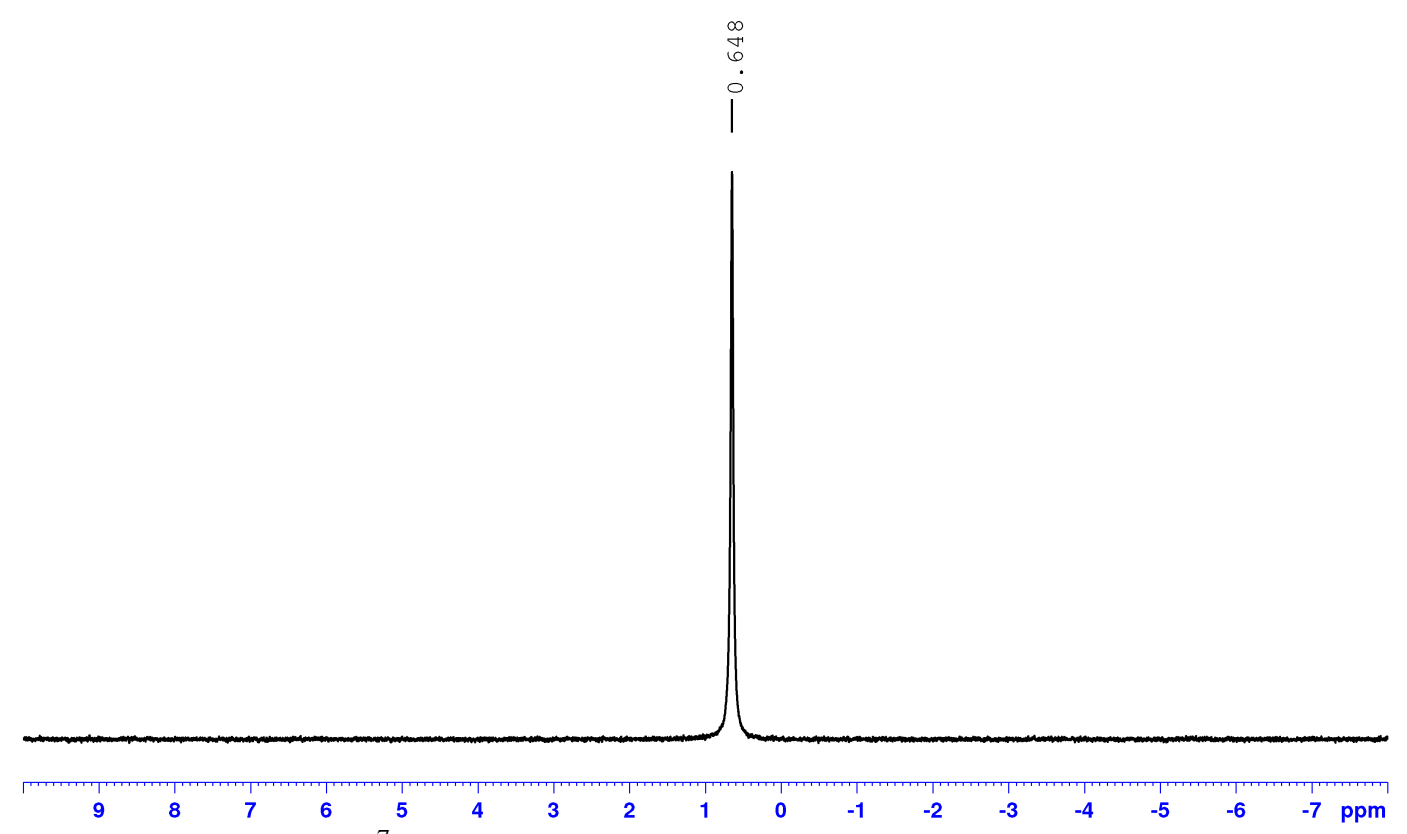

Figure ESI-27. ${ }^{7} \mathrm{Li}$ NMR spectrum of compound 3 in $\mathrm{d}_{8}$-THF at $298 \mathrm{~K}$.

\section{Addition reaction of $\mathrm{LiPh}$ towards $\mathrm{PhNC}(\mathrm{H}) \mathrm{NPh}$ in presence of $\mathrm{NBu}_{4} \mathrm{Cl}$}

To a solution of $\mathrm{PhC}(\mathrm{H}) \mathrm{NPh} 1 \mathrm{a}(0.0063 \mathrm{~g}, 0.035 \mathrm{mmol}), \mathrm{NBu}_{4} \mathrm{Cl}(0.0097 \mathrm{~g}, 0.035$ mmol) and $\mathrm{FeCp}_{2}(0.005 \mathrm{~g}, 0.027 \mathrm{mmol})$ as internal standard in $\mathrm{d}_{8}$-THF, equimolecular amounts of $\mathrm{LiPh}(0.0029,0.035 \mathrm{mmol})$ were added. Yield for the addition product (50\%) was calculated by integration of the ${ }^{1} \mathrm{H}$ NMR spectrum registered.

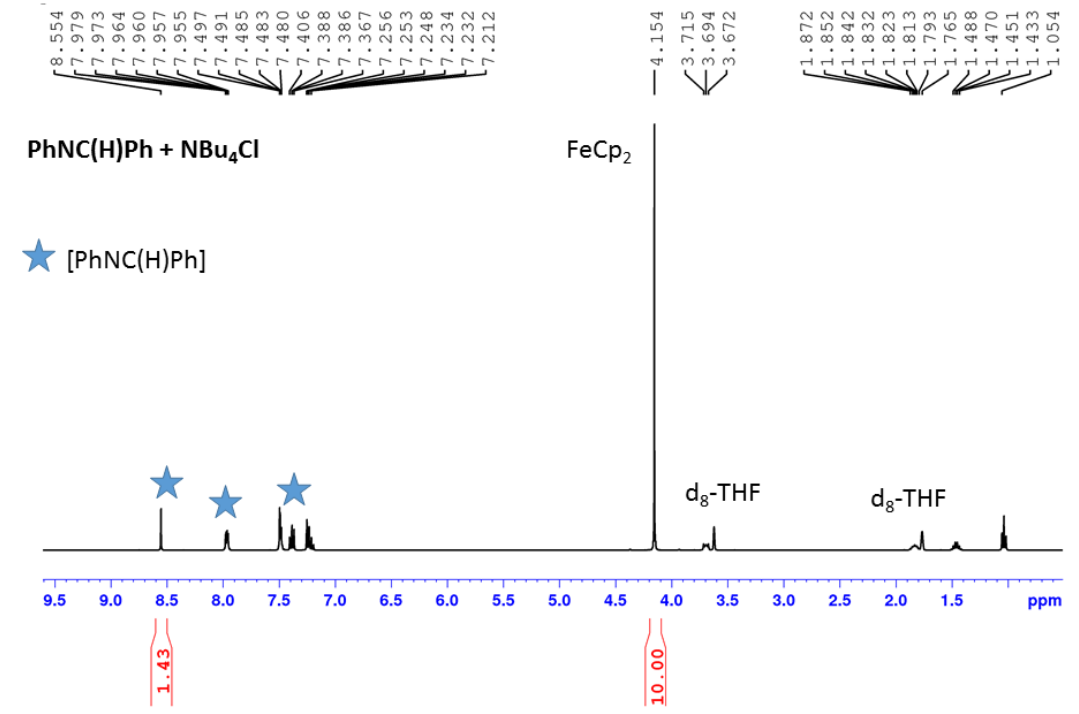

Figure ESI-28. ${ }^{1} \mathrm{H}$ NMR spectrum of the reaction mixture $\mathrm{PhNC}(\mathrm{H}) \mathrm{Ph}$ and $\mathrm{NBu}_{4} \mathrm{Cl}$ in $\mathrm{d}_{8}$-THF at $298 \mathrm{~K}$ before addition of PhLi. 


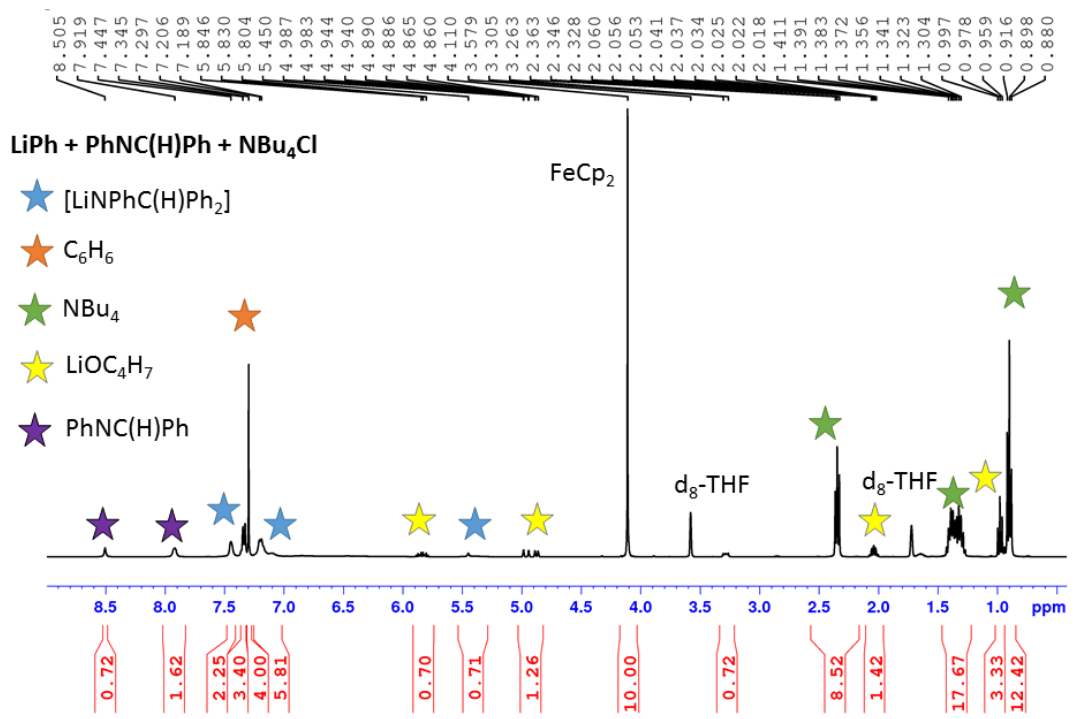

Figure ESI-29. ${ }^{1} \mathrm{H}$ NMR spectrum of the reaction mixture $\mathrm{LiPh}, \mathrm{NBu}_{4} \mathrm{Cl}$ and $\mathrm{PhNC}(\mathrm{H}) \mathrm{Ph}$ in $\mathrm{d}_{8}-\mathrm{THF}$ at $298 \mathrm{~K}$.

\section{DOSY Studies}

To a solution of $\mathrm{PhC}(\mathrm{H}) \mathrm{NPh}(\mathbf{1 a}, 0.0063 \mathrm{~g}, 0.035 \mathrm{mmol}), \mathrm{NBu}_{4} \mathrm{Cl}(0.0097 \mathrm{~g}, 0.035$ $\mathrm{mmol})$ and tetramethylsilane $(4.8 \mu \mathrm{L}, 0.035 \mathrm{mmol})$ as internal standard in $0.7 \mathrm{~mL}$ of $\mathrm{d}_{8}$-THF, equimolecular amounts of $\mathrm{LiPh}(0.0029,0.035 \mathrm{mmol})$ were added. The reaction mixture was investigated by ${ }^{1} \mathrm{H}$ DOSY NMR. Data were processed using the external calibration curve (ECC) for dissipated spheres and ellipsoids elaborated by Stalke. $^{9}$

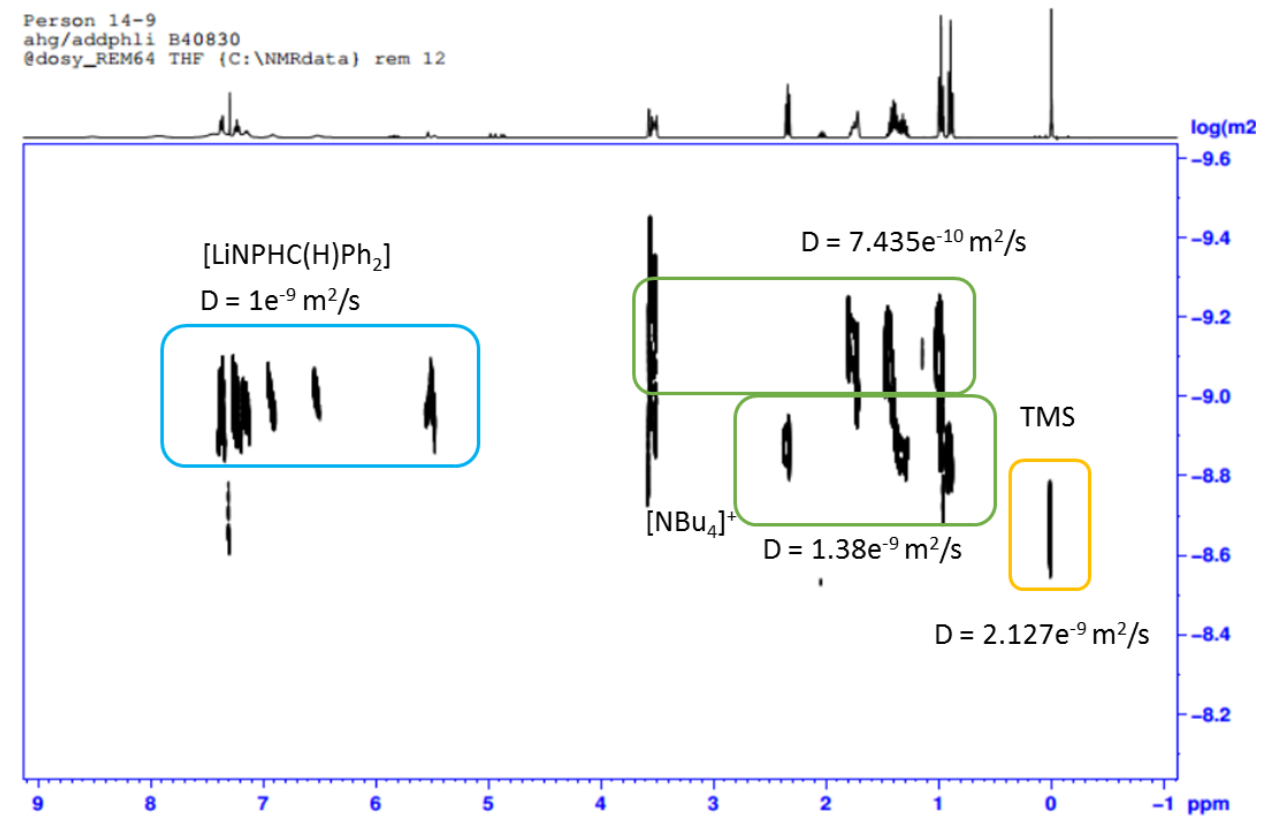

Figure ESI-30. ${ }^{1} \mathrm{H}$ DOSY NMR spectrum of the reaction mixture $\mathrm{LiPh}, \mathrm{NBu}_{4} \mathrm{Cl}$ and $\mathrm{PhNC}(\mathrm{H}) \mathrm{Ph}$ in $\mathrm{d}_{8}-\mathrm{THF}$ at $298 \mathrm{~K}$. 
Table ESI-2. Estimation of the $\mathrm{Mw}$ of compound generated by reaction of $\mathrm{LiPh}$ (40 $\mathrm{mM}), \mathrm{NBu}_{4} \mathrm{Cl}$ and $\mathrm{PhNC}(\mathrm{H}) \mathrm{Ph}$ in $\mathrm{d}_{8}$-THF at $298 \mathrm{~K}$.

\begin{tabular}{|c|c|c|}
\hline Mw estimated by & \multicolumn{2}{|c|}{ Proposed species, Mw, (\%error) } \\
\hline \multirow{3}{*}{$\begin{array}{l}\text { Aromatic signals } \\
367 \mathrm{~g} / \mathrm{mol}\end{array}$} & $\begin{array}{l}{\left[\mathrm{LiCl}\left\{\mathrm{N}(\mathrm{Ph}) \mathrm{CHPh}_{2}\right\}(\mathrm{THF})\right]^{-},} \\
372.84 \mathrm{~g} / \mathrm{mol}, \mathbf{( 2 \% )}\end{array}$ & $\begin{array}{l}{\left[\mathrm{LiCl}\left\{\mathrm{N}(\mathrm{Ph}) \mathrm{CHPh}_{2}\right\}(\mathrm{THF})_{2}\right]^{-},} \\
444.95 \mathrm{~g} / \mathrm{mol}, \mathbf{( 1 8} \%)\end{array}$ \\
\hline & $\begin{array}{l}{\left[\mathrm{Li}\left\{\mathrm{N}(\mathrm{Ph}) \mathrm{CHPh}_{2}\right\}(\mathrm{THF})_{3}\right]} \\
481.61 \mathrm{~g} / \mathrm{mol},(\mathbf{2 4} \%)\end{array}$ & $\begin{array}{l}{\left[\mathrm{Li}\left\{\mathrm{N}(\mathrm{Ph}) \mathrm{CHPh}_{2}\right\}(\mathrm{THF})_{2}\right],} \\
409.5 \mathrm{~g} / \mathrm{mol},(\mathbf{1 0} \%)\end{array}$ \\
\hline & \multicolumn{2}{|c|}{$\left[\mathrm{N}(\mathrm{Ph}) \mathrm{CHPh}_{2}\right]^{-}, 258.34 \mathrm{~g} / \mathrm{mol},(-\mathbf{4 2} \%)$} \\
\hline $\begin{array}{c}\text { Alkyl signals } \\
211 \mathrm{~g} / \mathrm{mol}\end{array}$ & \multicolumn{2}{|c|}{$\left[\mathrm{NBu}_{4}\right], 242.47 \mathrm{~g} / \mathrm{mol},(\mathbf{1 3} \%)$} \\
\hline
\end{tabular}

\section{References}

(1) Abbott, A. P.; Capper, G.; Davies, D. L.; Rasheed, R. K.; Tambyrajah, V. Chem. Commun., 2003, 70 .

(2) Gridd, R.; McMeekin, P.; Sridharan, V. Tetrahedron, 1995, 51, 13331.

(3) Love, B. E.; Jones, E. G. J. Org. Chem., 1999, 64, 3755.

(4) Wehman, E.; Jastrzebski, J. T. B. H.; Ernsting, J.-M.; Grove, D. M.; Koten, G. V. J. Organomet. Chem., 1988, 353, 133.

(5) (a) Cliffe, I. A.; Crossley, R.; Shepherd, R. G. Synthesis, 1985, 1138; (b) Ciganek, E. J. Org. Chem., 1992, 57, 4521; (c) Samec, J. S. M.; Bäckvall, J.-E. Chem. Eur. J., 2002, 8, 2955; (d) Trifonova, A.; Diesen, J. S.; Chapman, C. J.; Andersson, P. G. Org. Lett., 2004, 6, 382; (e) Hatano, M.; Suzuki, S.; Ishihara, K. J. Am. Chem. Soc., 2006, 128, 9998; (f) Malkov, A. V.; Stoncius, S.; MacDougall, K. N.; Mariani, A.; McGeoch, G. D.; Kocovsky, P. Tetrahedron, 2006, 62, 264; (g) Lamas, M.-C.; Vaillard, S. E.; Wibbeling, B.; Studer, A. Org. Lett., 2010, 12, 2072.

(6) CrysAlisPro; Oxford Diffraction: Oxford, UK 2008.

(7) Sheldrick, G. Acta Cryst., 2015, C71, 3-8.

(8) (a) Dauphinee, G. A.; Forrest, T. P. Can. J. Chem., 1978, 56, 632; (b) Forrest, T. P.; Dauphinee, G. A.; Deraniyagala, S. A. Can. J. Chem., 1985, 63, 412; (c) Goldstein, S. W.; Dambek, P. J. Synthesis, 1989, 221.

(9) Neufeld, R.; Stalke, D. Chem. Sci., 2015, 6, 3354. 